Rebolledo López, D. C., y Lores Ochoa, D. C. (2021). Evaluación espaciotemporal de la cobertura vegetal del parque nacional Henri Pittier, Venezuela. GeoFocus, Revista Internacional de Ciencia y Tecnología de la Información Geográfica (Artículos), 28, 25-58. http://dx.doi.org/10.21138/GF.742

\title{
EVALUACIÓN ESPACIOTEMPORAL DE LA COBERTURA VEGETAL DEL PARQUE NACIONAL HENRI PITTIER, VENEZUELA
}

\author{
${ }^{1}$ DEISY COROMOTO REBOLLEDO LÓPEZ (D) y ${ }^{2}$ DILIA CELESTE LORES OCHOA \\ ${ }^{1}$ División de Estudios de Postgrado, Universidad de la Sierra Sur (UNSIS) \\ Guillermo Rojas Mijangos S/N, Esquina Av. Universidad, Ciudad Universitaria, Miahuatlán de Porfirio \\ Díaz, Oaxaca. México, C.P. 70805 \\ ${ }^{2}$ Gerencia Corporativa de Seguridad, Higiene y Ambiente, Petroquímica de Venezuela (PEQUIVEN) \\ Av.73 con calle 79, Zona Industrial Municipal Sur, Valencia, estado Carabobo, Venezuela. \\ 1deisyc.rebolledo@gmail.com y ${ }^{2}$ celeste.lores@gmail.com
}

\section{RESUMEN}

En este estudio se analizan cambios de cobertura vegetal del Parque Nacional Henri Pittier, Venezuela. El objetivo es la cuantificación de las variaciones de coberturas de las unidades de vegetación. El período de análisis es de ocho años, mediante tres imágenes (2010, 2014 y 2018). El mapa de referencia se obtiene mediante una imagen Landsat-7 ETM+ (2001) con validación de campo (2010). Los mapas de 2014 y 2018 se obtienen mediante sendas imágenes del satélite Landsat-8. Los resultados obtenidos demuestran que la cobertura del bosque nublado superior pasó de 9010 ha (2010) a 6963 ha (2018). El bosque nublado bajo varió de 32613 ha (2010) a 28423 ha (2018). La superficie de los herbazales se incrementó de 17274 ha (2010) a 25149 ha (2018). La tasa anual de cambio para las coberturas reafirma que los bosques pierden superficie y estas áreas son cubiertas de herbazales. Estos cambios ponen en riesgo la disponibilidad de los servicios ambientales.

Palabras claves: Matriz de detección de cambio; matriz de confusión; tasa anual de cambio; índice de concordancia de Kappa (k); clasificación supervisada; Parque Nacional Henri Pittier.

\section{TEMPORARY SPACE EVALUATION OF THE VEGETABLE COVERAGE OF THE HENRI PITTIER NATIONAL PARK, VENEZUELA}

\begin{abstract}
This study analyzes changes in the vegetation cover of the Henri Pittier National Park, Venezuela. The objective was the quantification of the cover variations of the vegetation units. The analysis period was eight years, using three images (2010, 2014 and 2018). The reference map was a Landsat-7 ETM+ image (2001) with field validation (2010). The 2014 and 2018 images correspond to the Landsat-8




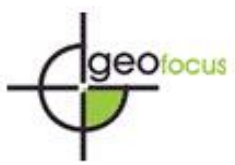

Rebolledo López, D. C., y Lores Ochoa, D. C. (2021). Evaluación espaciotemporal de la cobertura vegetal del parque nacional Henri Pittier, Venezuela. GeoFocus, Revista Internacional de Ciencia y Tecnología de la Información Geográfica (Artículos), 28, 25-58. http://dx.doi.org/10.21138/GF.742

satellite. The results obtained show that the upper cloud forest cover increased from 9010 ha (2010) to 6963 ha (2018). The low cloud forest ranged from 32613 ha (2010) to 28423 ha (2018). The area of the grasslands increased from 17274 ha (2010) to 25149 ha (2018). The Annual Rate of Change for the covers reaffirms that the forests lose surface and these areas are covered with grasslands. These changes put the availability of environmental services at risk.

Keywords: Change detection matrix; confusion matrix; annual exchange rate; Kappa concordance index (k); supervised classification; National Park Henri Pittier.

\section{Introducción}

La cobertura boscosa de Venezuela es amplia y diversa. Actualmente sigue fragmentándose por deforestación, tala y degradación. Estas afectaciones son múltiples y las principales causas de estas afectaciones son por cambios de usos del suelo. Entre las causas principales se identifican las siguientes: incremento de la pobreza, invasión de tierras, invasión hacia áreas protegidas, migración, expansión agrícola, minería, exploración de fuentes de energía y aprovechamiento forestal, políticas gubernamentales y corrupción, y disminución de supervisión y vigilancia ambiental, entre otras (Organización de las Naciones Unidas para la Agricultura y la Alimentación (FAO), 2000). Otra causa importante de pérdida de la cobertura vegetal en Venezuela son los incendios forestales los cuales son recurrentes, incontrolados y en su mayoría producidos por la acción humana. Según afirma Vielma (2020) durante la temporada de sequía (noviembre a abril) de 2019 y 2020, ocurrieron un número importante de incendios de vegetación en el territorio venezolano los cuales afectaron amplias superficies de terreno. Estos incendios estuvieron asociados tanto al uso del suelo como a los focos de calor (puntos de la superficie con altas temperaturas en comparación con las temperaturas del entorno, que indican la probabilidad de incendios en un área). Esta investigación señaló que para el caso del estado Aragua, específicamente para el Parque Nacional Henri Pittier (PNHP), los incendios estuvieron asociados al uso del fuego para quemar basura acumulada en centros urbanos, que se expandieron consumiendo la vegetación del parque.

Los incendios en el PNHP han sido estudiados con anterioridad y se han reconocido como recurrentes, incontrolados y con un comportamiento estacional en todo el territorio de Venezuela. Éstos ocurren durante los meses de mayor sequía (Abarca \& Quiroz, 2005), se inician en noviembre y culminan entre abril y mayo (Rebolledo, 2014). Según afirman Abarca y Quiroz (2005) entre las variables que contribuyen al aumento de los riesgos de incendios en la vertiente sur del PNHP, están las siguientes: los usos agrícolas (cultivo de caña de azúcar que es quemada antes de ser cosechada, como práctica agrícola), las prácticas de tiro miliares, los usos urbanos con quema de desechos orgánicos (hojarasca) y la recreación (fogatas que luego son mal apagadas, Rebolledo, 2014). Además, otros elementos que favorecen la ocurrencia de incendios de la vegetación dentro del área del parque es la presencia de coberturas vegetales constituidas por herbazales y bosques caducifolios. Estas unidades de vegetación están compuestas por especies vegetales de fácil ignición y se encuentran vecinas a zonas con los usos del suelo antes identificados, así como a las vías de acceso asfaltadas y a los senderos que cruzan o atraviesan el área de estudio. Según afirman Abarca y Quiroz (2005) más de 50 \% del área de la cuenca hidrográfica del río El Limón del PNHP 
Rebolledo López, D. C., y Lores Ochoa, D. C. (2021). Evaluación espaciotemporal de la cobertura vegetal del parque nacional Henri Pittier, Venezuela. GeoFocus, Revista Internacional de Ciencia y Tecnología de la Información Geográfica (Artículos), 28, 25-58. http://dx.doi.org/10.21138/GF.742

(vertiente sur), se encuentran bajo condiciones de Riesgo Moderado, alrededor de $30 \%$ en Riesgo Bajo y el resto del área se distribuyó entre Riesgo Alto y Muy Alto.

En Venezuela, como en otros países de América Latina, aunque se reconoce la importancia de la preservación o conservación de las áreas cubiertas de vegetación, tanto a escala local, regional, nacional como global, las actividades antrópicas han afectado, están afectando y, posiblemente, seguirán afectando los ecosistemas, indistintamente si están o no bajo alguna figura de protección. Esto se muestra en el mismo PNHP. Este parque fue el primer parque nacional decretado en Venezuela (República de Venezuela, 1937) cuyo objetivo fue su preservación y conservación y, aun así, está reportado como un parque amenazado por diversas causas antrópicas y entre éstas los incendios forestales como la principal causa (Muñoz et al., 2006).

¿Por qué es importante el estudio de los incendios de cobertura vegetal del PNHP? Porque se ha identificado a los incendios forestales como uno de los causantes principales de la pérdida de diversidad biológica y de los servicios ecosistémicos tanto a nivel global (Armenteras et al., 2020), regional, nacional como local. En el área que hoy día se identifica como el PNHP se han reportado cambios en las unidades de cobertura vegetal desde la época en que Humboldt (1800) recorrió el estado Aragua-Venezuela (citado por Abarca \& Quiroz, 2005) y éstos no han cesado.

Las áreas de bosque cuando se pierden se remplazan por herbazales, también llamadas sabanas tropical (Silva, 2003), ocasionando una disminución radical de los servicios ambientales. Si se comparan ambas unidades de cobertura de vegetación, según las estimaciones del capital natural reportadas por Costanza et al. (1997) se muestra sus diferencias. Estos autores identificaron para los bosques 14 servicios ambientales de 17 y para los herbazales solo 10. En sus esfuerzos para cuantificarlos económicamente reportaron 959 \$/ha/año para los bosques y 232 \$/ha/año para los herbazales, como valores económicos. También cuantificaron el valor de flujo de ambos ecosistemas y así para los primeros reportaron 4706 \$/año x $10^{6}$ y para los herbazales 906 \$/año x $10^{6}$. Es decir, al suceder esos cambios de coberturas vegetales se están perdiendo servicios ambientales y con éstos, capital natural.

A fin de proteger a los ecosistemas boscosos se decretan áreas con alguna figura de protección como monumentos naturales, reservas y refugios de fauna silvestre y parques nacionales (García \& Silva, 2013). Los parques nacionales en Venezuela, en cuanto al uso del suelo son las áreas de protección más restrictivas y tienen como objetivos la preservación y la conservación de: su diversidad biológica, sus procesos ecológicos y sus servicios ambientales (Naveda, 2015). Estas áreas son de mucha importancia porque la protección de ecosistemas le garantiza a la sociedad diversos bienes y servicios ambientales. Entre los servicios ecosistémicos se han identificado protección de cuencas, secuestro de carbono, espacios para la recreación, autoabastecimiento y generación de materia prima, agua; y su importancia para la sustentabilidad de la vida en la Tierra (Costanza et al., 1997).

El PNHP se encuentra ubicado en la Serraría del Litoral de la Cordillera de La CostaVenezuela y así como lo expresa el Plan de Ordenamiento y Reglamento de Uso del Parque Nacional Henri Pittier (Ministerio de la Secretaría de la Presidencia (MSP), 1995), artículo $4^{\circ}$ El objetivo fundamental del PNHP es preservar y conservar muestras relevantes y representativas de los ecosistemas y paisajes de montaña de la porción central de la Serraría del Litoral de la Cordillera de la Costa, mediante el cumplimiento de varios objetivos específicos. 


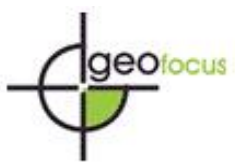

Rebolledo López, D. C., y Lores Ochoa, D. C. (2021). Evaluación espaciotemporal de la cobertura vegetal del parque nacional Henri Pittier, Venezuela. GeoFocus, Revista Internacional de Ciencia y Tecnología de la Información Geográfica (Artículos), 28, 25-58. http://dx.doi.org/10.21138/GF.742

Los bosques nublados son de mucha importancia por los servicios ecosistémicos que le brindan a la sociedad. Entre estos servicios se han identificado los de provisión, regulación, cultural y soporte (Rosa et al., 2004). Entre los que han sido reconocidos como de mayor importancia a nivel local son los servicios de provisión y regulación; aportados por las coberturas vegetales y suelos de las cuencas hidrográficas y por su valor hidrológico como garante del flujo permanente tanto para la sustentabilidad de los ecosistemas del parque como de los ecosistemas circunvecinos y para el suministro de agua para el consumo humano. Los cuerpos de agua de la vertiente norte constituyen la única fuente del vital líquido tanto para el autoabastecimiento de pobladores como para las actividades agrícolas y los servicios turísticos (posadas, hoteles y restaurantes); y para los habitantes de la vertiente sur son complementarios (Rebolledo, 2014).

Los estudios de cambio de cobertura vegetal son de interés, entre otros objetivos, porque han permitido evaluar las tendencias espaciotemporales de procesos como la deforestación y la degradación ambiental, provocados por actividades humanas (Osuna et al., 2015). Esto, de igual manera, lo han identificado Maillard et al. (2019) al expresar que los procesos de deforestación y degradación son factores importantes que deben tener prioridad en la investigación por su gran impacto sobre la biodiversidad y en el cambio climático.

El surgimiento de herramientas de Teledetección y de Sistemas de Información Geográfica (SIG), dado que proveen una visión sinóptica espacialmente explícita de los atributos de la superficie del planeta, ha constituido una fuente de información imprescindible para la caracterización de la cobertura y/o del uso del territorio a distintas escalas y, a su vez, para la identificación de los cambios en los usos del suelo tanto por efectos naturales como por actividades antrópicas, así como también para la elaboración de cartografía y el seguimiento del uso del suelo en zonas o áreas de interés. Estas herramientas, sumadas a otras geotecnologías tales como los sistemas de posicionamiento global (GPS por sus siglas en inglés), los drones o las estaciones totales, entre otras, ofrecen una nueva perspectiva para la cartografía y monitoreo del territorio y en especial para el cambio de uso del suelo y la cobertura vegetal.

En este estudio se realizó un análisis de la cobertura vegetal utilizando como verdad terreno el mapa de cobertura vegetal de Rebolledo (2014) y la interpretación visual de imágenes Landsat 8 de dos fechas, del 10 de marzo de 2014 y del 21 de marzo de 2018. Éstas fueron obtenidas del United States Geological Survey (USGS) (http://glovis.usgs.gov). Esta investigación permitió analizar los cambios en la cobertura vegetal del PNHP para darle a conocer a la sociedad lo que está sucediendo y así los tomadores de decisiones asuman las acciones adecuadas para detener las pérdidas de bosques y simultáneamente proteger las fuentes de suministros de los servicios ambientales como garantes de la supervivencia de las comunidades que requieren dichos servicios para su sustentabilidad.

\section{2. Área de Estudio}

El PNHP está ubicado en el tramo central de la Cordillera de La Costa entre las coordenadas $10^{\circ} 14^{\prime} 25^{\prime \prime} \mathrm{N}, 10^{\circ} 32^{\prime} 40^{\prime \prime} \mathrm{N}, 67^{\circ} 27^{\prime} 36^{\prime} \mathrm{W}$ y $67^{\circ} 52^{\prime} 54^{\prime \prime} \mathrm{W}$, en los estados Aragua y CaraboboVenezuela y cubre una superficie aproximada de 107.7 ha (Rebolledo, 2014). La mayor superficie se localiza en Aragua y una parte pequeña en Carabobo (Figura 1). 


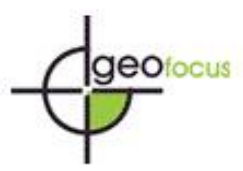

Rebolledo López, D. C., y Lores Ochoa, D. C. (2021). Evaluación espaciotemporal de la cobertura vegetal del parque nacional Henri Pittier, Venezuela. GeoFocus, Revista Internacional de Ciencia y Tecnología de la Información Geográfica (Artículos), 28, 25-58. http://dx.doi.org/10.21138/GF.742

En el PNHP otro aspecto relevante es su régimen de precipitación. La mayor cantidad de precipitación al año es durante el mes de agosto y, en cambio, entre enero y febrero se presentan las menores precipitaciones. La pluviosidad media anual oscila entre $1650 \mathrm{~mm}$ a $2200 \mathrm{~mm}$ y la temperatura media anual entre $19^{\circ} \mathrm{C}$ y $21^{\circ} \mathrm{C}$ (Huber, 1986).

La temperatura es muy variada debido a sus diversos pisos altitudinales. El clima, según la clasificación de Köppen, está constituido por tres zonas climáticas tropicales: éstas son húmeda o lluviosa, seca y húmeda mesotérmica. La diversidad de condiciones físicas, químicas y biológicas a lo largo del gradiente altitudinal constituye las condiciones óptimas para diversas formaciones vegetales. Este parque comprende varios pisos altitudinales y a su vez se divide en dos vertientes, la norte y la sur.

Los pisos altitudinales en la vertiente norte abarcan desde el litoral rocoso hasta los bosques nublados a una altura de $2400 \mathrm{msnm}$ (cerro El Cenizo) y, en la vertiente sur, desde los $2400 \mathrm{msnm}$ hasta $450 \mathrm{msnm}$. Las unidades de vegetación de la vertiente norte en su parte más baja están constituidas por cardonal y espinar. A medida que se va subiendo desde las zonas más bajas (desde la ciudad de Maracay) a las más altas a través de las carreteras del PNHP se atraviesan bosques caducifolios y semi-caducifolios con ciclos anuales de lluvia y sequía, que contrastan, para luego adentrarse en bosques nublados. Éste es uno de los ecosistemas más complejos y particulares del mundo con neblina y lluvia casi permanente (Fernández, 1997).

Otra de las características del PNHP es su gran valor para el país porque alberga un elevado número de aves de importancia patrimonial, así como familias y gremios alimentarios indicadores de la calidad ambiental (Verea \& Solorzano, 2011).

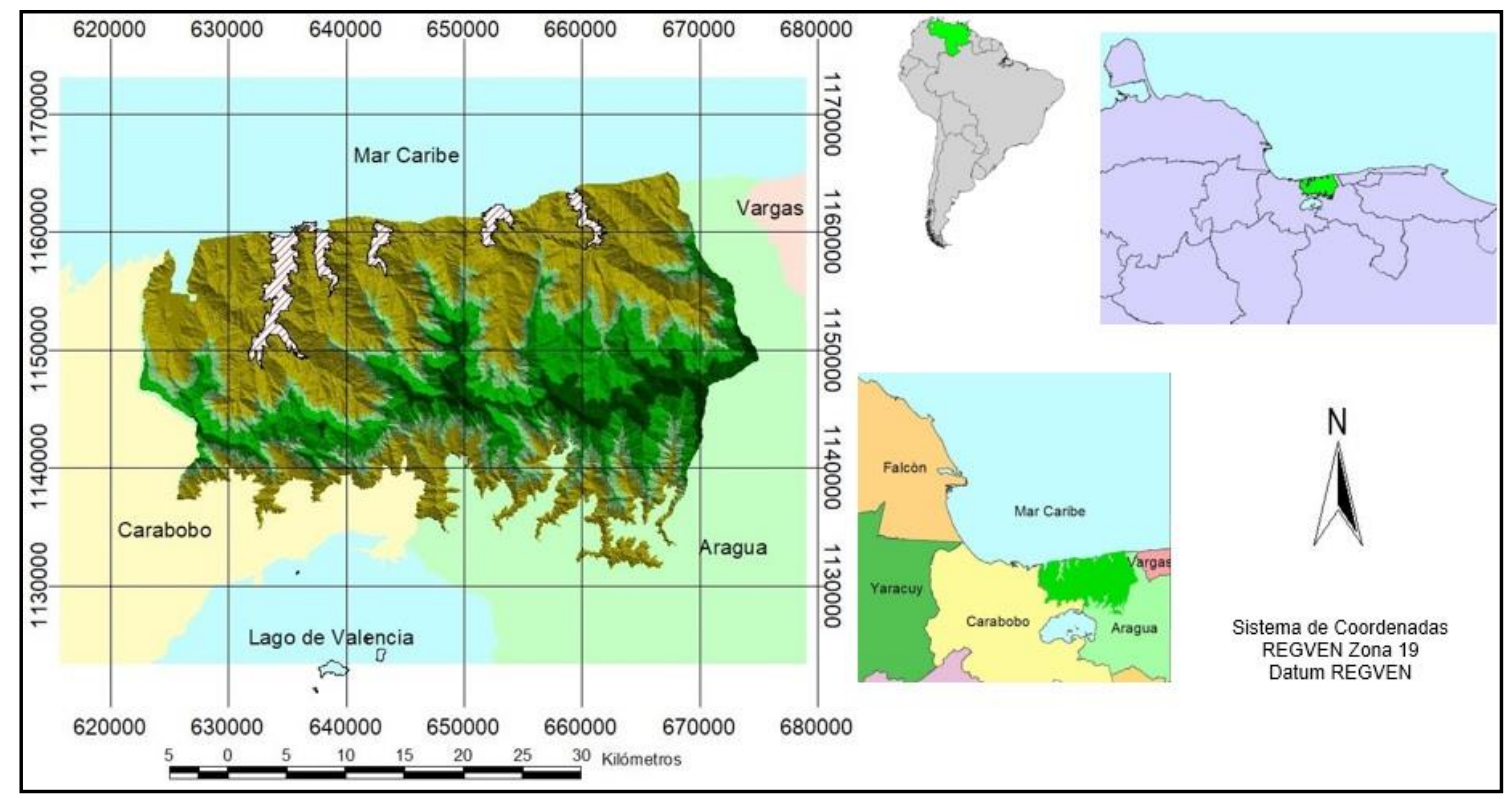

Figura 1. Ubicación del área de estudio.

Fuente: Elaboración propia. 


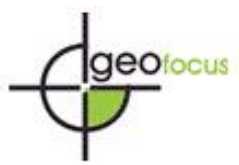

Rebolledo López, D. C., y Lores Ochoa, D. C. (2021). Evaluación espaciotemporal de la cobertura vegetal del parque nacional Henri Pittier, Venezuela. GeoFocus, Revista Internacional de Ciencia y Tecnología de la Información Geográfica (Artículos), 28, 25-58. http://dx.doi.org/10.21138/GF.742

\section{Materiales y métodos}

El análisis de la variación de los cambios de la cobertura boscosa del PNHP se realizó considerando una ventana temporal de ocho años (2010 al 2018), tomando como punto de partida el mapa de Rebolledo (2014) y el procesamiento de dos imágenes Landsat 8, una tomada el 10 de marzo de 2014 y otra el 21 de marzo de 2018. Estas escenas fueron obtenidas desde la galería de imágenes del USGS (http://glovis.usgs.gov), de acceso libre.

La elaboración del mapa de cobertura vegetal 2010 (Figura 2) se realizó a partir de la producción de dos mapas o coberturas base como productos intermedios. Éstos fueron: (1) el vectorizado a partir del mapa de vegetación rásterizado, escala 1:50000, del Parque Nacional Henri Pittier y (2) el originado a partir de la clasificación supervisada de la imagen Landsat7 ETM+ 004/053 del año 2001 (Tabla 1) y un exhaustivo recorrido de campo durante el año 2010 con expertos en reconocimiento de vegetación (Rebolledo, 2014).

Esta información generada se complementó con la revisión de los ortofotomapas a escala 1:12000 de Ocumare, Colonia Tovar y Girardot (Instituto Geográfico Venezolano Simón Bolívar (IGVSB), 1998) producidos por el Institut Cartogràfic de Catalunya (1999a, b y c) para la identificación de herbazales ubicados por encima de los $1000 \mathrm{msnm}$ de la vertiente sur y por encima de los $750 \mathrm{msnm}$ de la vertiente norte; los bosques de galerías fueron definidos con la ayuda de la capa de información de la hidrografía, en especial en la vertiente sur (Rebolledo, 2014). La delimitación de las unidades de cobertura vegetal distintas a los bosques nublados en la vertiente norte fue definida de acuerdo con (Beebe \& Crane (1947) citados por Rebolledo, 2014).

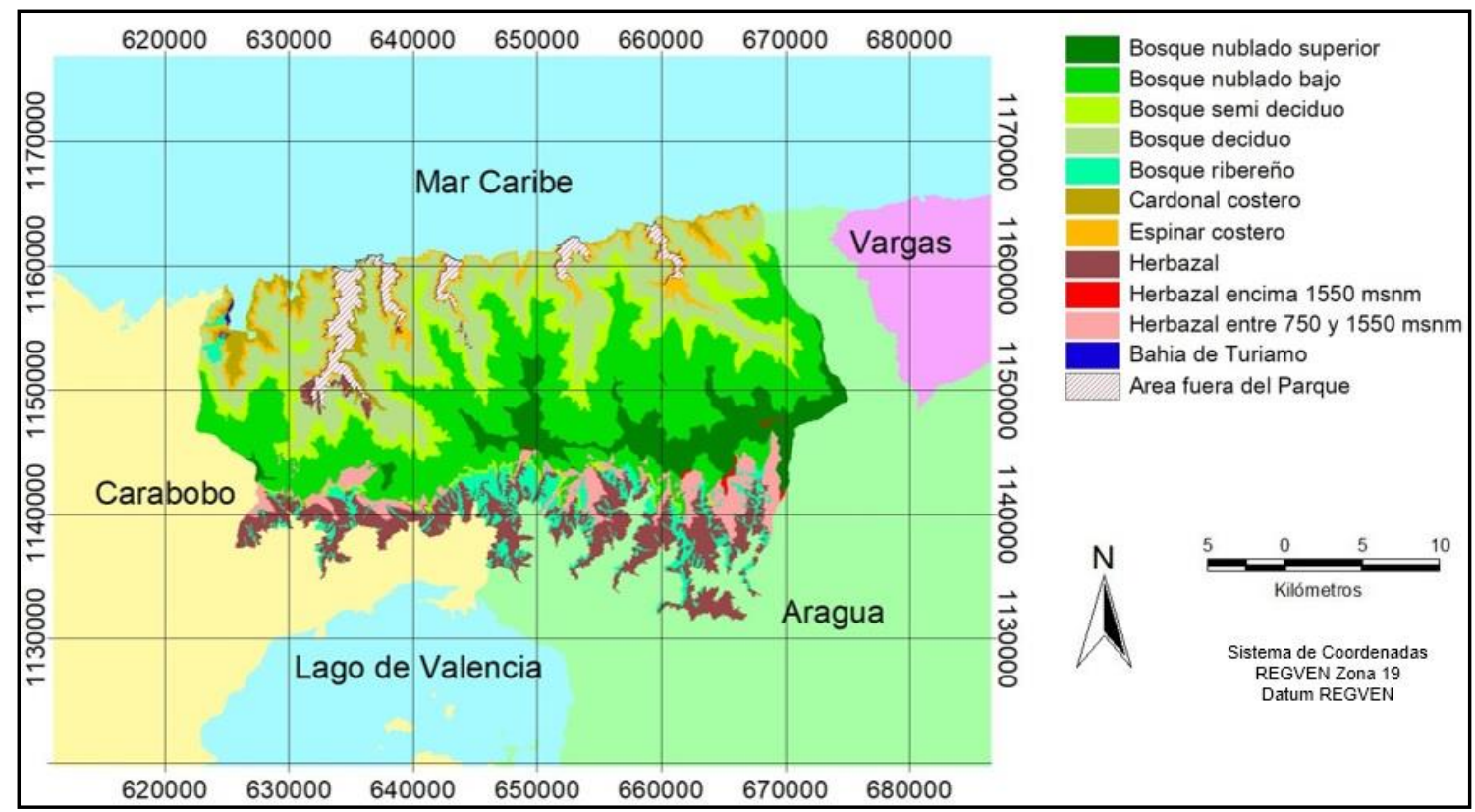

Figura 2. Mapa de cobertura vegetal del PNHP: Año 2010.

Fuente: Rebolledo (2014). 


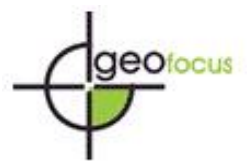

Rebolledo López, D. C., y Lores Ochoa, D. C. (2021). Evaluación espaciotemporal de la cobertura vegetal del parque nacional Henri Pittier, Venezuela. GeoFocus, Revista Internacional de Ciencia y Tecnología de la Información Geográfica (Artículos), 28, 25-58. http://dx.doi.org/10.21138/GF.742

La delimitación de los bosques nublados se efectuó tomando en cuenta el criterio de Cardozo (1999) y con las curvas de nivel vectorizadas cada 20 metros, escala 1:25000 del PNHP (Inparques, 2000). Además, se realizaron salidas de campo en la vertiente sur y en relación a la verificación de la cobertura vegetal de la vertiente norte. Asimismo, se efectuaron salidas de campo por el sendero de la Estación de Rancho Grande y Portachuelo, las carreteras Maracay-Choroní, MaracayOcumare de la Costa de Oro, y una revisión del mapa con el botánico Dr. Cardozo de la Facultad de Agronomía de la Universidad Central de Venezuela.

Tabla 1. Atributos de la Imagen Landsat 7 ETM+ 2001.

\begin{tabular}{llll}
\hline \multicolumn{1}{r}{ Atributo } & Valor del atributo & \multicolumn{1}{c}{ Atributo } & Valor del atributo \\
\hline WRS_PATH & 004 & Sensor & ETM+ \\
WRS_ROW & 053 & Formato & Geotiff \\
Fecha & $14 / 03 / 2001$ & Bandas & $1,2,3,4,5,7$ \\
Datum & WGS84 & Nivel de procesamiento & L1G \\
Elipsoide & WGS84 & Resolución espacial & $30 \mathrm{~m}$ \\
Proyección & UTM & Resolución radiométrica & 8 bits \\
Huso & 19 & Resolución temporal & 16 días \\
\hline
\end{tabular}

Fuente: Elaborado con base en Rebolledo (2014) y http://glovis.usgs.gov.

La generación de los mapas de cobertura vegetal tanto para el año 2014 como para el 2018 se hizo mediante clasificación supervisada.

Tabla 2. Atributos de las imágenes Landsat 8 del 2014 y 2018.

\begin{tabular}{lcc}
\hline & Imagen Landsat8 2014 & Imagen Landsat8 2018 \\
\hline Atributo & Valor del Atributo & Valor del Atributo \\
\hline WRS_PATH & 4 & 4 \\
WRS_ROW & 53 & 53 \\
Fecha & $10 / 3 / 2014$ & $21 / 3 / 2018$ \\
Datum & WGS84 & WGS 84 \\
Elipsoide & WGS84 & WGS 84 \\
Proyección & UTM & UTM \\
Huso & 19 & 19 \\
Sensor & OLI_TIRS & OLI_TIRS \\
Formato & Geotiff & Geotiff \\
Bandas & $1,2,3,4,5,6,7,8,9,10,11$ & $1,2,3,4,5,6,7,8,9,10,11$ \\
Nivel de procesamiento & L1TP & L1TP \\
Resolución espacial & 30 & 30 \\
Resolución radiométrica & 12 bits & 12 bits \\
Resolución temporal & 16 días & 16 días \\
\hline
\end{tabular}

Fuente: Elaborado con base en http://glovis.usgs.gov. 


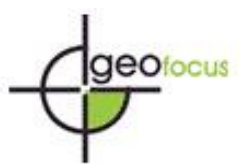

Rebolledo López, D. C., y Lores Ochoa, D. C. (2021). Evaluación espaciotemporal de la cobertura vegetal del parque nacional Henri Pittier, Venezuela. GeoFocus, Revista Internacional de Ciencia y Tecnología de la Información Geográfica (Artículos), 28, 25-58. http://dx.doi.org/10.21138/GF.742

Las imágenes fueron procesadas con el software Erdas Imagine 2014 y la información vectorial con ArcGIS 10.5. La metodología llevada a cabo fue: definición de leyenda, procesamiento digital de información, clasificación supervisada, generación del mapa de cobertura para los años de estudio, validación de la clasificación y evaluación de los cambios de cobertura. A continuación, se reseña de cada una de las actividades realizadas.

\subsection{Definición de la leyenda}

Para definir la leyenda se tomaron las unidades de cobertura vegetal obtenidas por Rebolledo (2014) (Tabla 3).

Tabla 3. Unidades de vegetación del PNHP.

\begin{tabular}{llll}
\hline Siglas & Descripción & Siglas & Descripción \\
\hline Bns & Bosque nublado superior & $\mathrm{Cc}$ & Cardonal costero \\
$\mathrm{Bnb}$ & Bosque nublado bajo & $\mathrm{Ec}$ & Espinar costero \\
$\mathrm{Bsd}$ & Bosque semi-caducifolio & $\mathrm{H}$ & Herbazal ubicado por debajo de los $750 \mathrm{msnm}$ \\
$\mathrm{Bd}$ & Bosque caducifolio & $\mathrm{H}_{750}$ & Herbazal ubicado entre 750 y $1550 \mathrm{msnm}$ \\
$\mathrm{Br}$ & Bosque ribereño & $\mathrm{H}_{1550}$ & Herbazal por encima de los $1550 \mathrm{msnm}$ \\
\hline
\end{tabular}

Fuente: Elaborado con base en Rebolledo (2014).

\subsection{Procesamiento digital de la información}

Las imágenes del 2014 y 2018, descritas en la Tabla 2, fueron reproyectadas al sistema de referencia de la Red Geodésica Venezolana (REGVEN). Luego se realizó un recorte para generar una imagen que abarcara únicamente el área en estudio. Una vez obtenida la sub-escena correspondiente al área de estudio, se procedió a realizar la corrección geométrica de la imagen utilizando el método de remuestreo del vecino más cercano (nearest neighbour), ya que supone una menor transformación de los niveles digitales originales en la imagen al no introducir promedios. La combinación de bandas utilizadas fue la 7-5-3. Dicha selección se basó en la gráfica de firmas espectrales, observándose una clara separación entre clases de coberturas.

\subsection{Clasificación supervisada de las imágenes}

Una vez corregidas las imágenes se procedió a la realización de la clasificación supervisada, para lo cual se seleccionaron sobre la imagen original grupos de píxeles que representaban patrones de las diferentes clases temáticas. El método de agrupamiento utilizado fue paramétrico y la regla de decisión de máxima probabilidad. Las áreas de entrenamiento para cada clase se digitalizaron sobre cada una de las escenas. Su selección se realizó considerando las mismas premisas utilizadas por Rebolledo (2014). En este contexto la ubicación de las unidades de cobertura vegetal del PNHP se complementó con los pisos altitudinales expuestos para el PNHP por Beebe y Crane (1948) y Cardozo (1999).

Finalizado el procedimiento de recolección de muestras o áreas de entrenamiento, mediante el software Erdas Imagine 2014 se realizó un barrido por toda el área de la imagen del 2014 y del 2018. Este procedimiento asignó a cada pixel sus categorías en función de sus características 


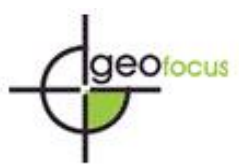

Rebolledo López, D. C., y Lores Ochoa, D. C. (2021). Evaluación espaciotemporal de la cobertura vegetal del parque nacional Henri Pittier, Venezuela. GeoFocus, Revista Internacional de Ciencia y Tecnología de la Información Geográfica (Artículos), 28, 25-58. http://dx.doi.org/10.21138/GF.742

espectrales y generó una nueva imagen clasificada según las clases que le fueron asignadas (Tabla $3)$.

Después de haber obtenido las imágenes clasificadas para cada año, a éstas se le realizaron remuestreos y así eliminar el llamado efecto "sal y pimienta", es decir, pequeñas islas de píxeles o píxeles aislados dentro de grandes áreas de una clase (Serra et al., 2008). El filtro utilizado fue Majority 3x3, el cual reemplaza las celdas de un ráster en función de la mayoría de sus celdas contiguas, posteriormente se vectorizó de manera automática mediante las herramientas de ArcGIS para calcular las superficies de cada unidad de cobertura.

\subsection{Validación de la clasificación}

La validación de la clasificación fue realizada mediante la Matriz de Confusión o Matriz de Error. Esto permitió la valoración de la exactitud individual de cada clase y la exactitud total de la clasificación. Estas matrices son un arreglo que expresa el número de unidades de muestras asignadas a una clase particular, en una clasificación con relación al número de unidades de muestras asignadas a la misma categoría, clase o unidad; pero en otra clasificación que es considerada como correcta (datos de referencia).

En esta matriz, las columnas usualmente representan los datos de referencia, en tanto que las filas indican la clasificación generada a partir de los datos de percepción remota. La Matriz de Error es una forma de representar la exactitud de un mapa en el sentido de que la exactitud de cada categoría está descrita por medio de los errores de comisión y omisión. Los errores de comisión explican las coberturas del mapa que no coincidieron con la realidad. Éstos se observan a la derecha de la matriz. Los errores de omisión lo conforman los residuales de las columnas ubicados en la parte inferior de la matriz e indican las coberturas que no se incluyeron en el mapa.

Adicionalmente, la exactitud total de una clasificación puede ser evaluada a través del Índice de Concordancia de Kappa (K). Éste es un estadístico que mide la diferencia entre la exactitud lograda en la clasificación con un clasificador automático y la que ha de lograrse mediante una clasificación correcta con un clasificador aleatorio.

\subsection{Evaluación de los cambios de cobertura}

La evaluación de los cambios de cobertura se realizó a través del análisis post-clasificatorio superponiendo los mapas temáticos de cada fecha para generar matrices de detección de cambios (Eastman et al., 1995). Esto se hizo comparando el mapa de 2010 con los mapas del 2014 y del 2018 y, a su vez, el mapa del 2014 con el mapa del 2018. La matriz de detección de cambios permitió la realización del cálculo de la conjunción lógica de todas las combinaciones posibles de las clases representadas en dos mapas. Es un arreglo similar al de la matriz de error y se hace comparando mapas de diferentes fechas.

La diagonal superior de la matriz representa píxeles de la misma clase en ambas fechas, es decir píxeles sin cambio (Eastman et al., 1995). Los píxeles de una clase que se encuentran fuera de la diagonal representan los cambios entre los dos años o fechas. Así mismo, si se encuentran en las 


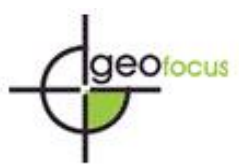

Rebolledo López, D. C., y Lores Ochoa, D. C. (2021). Evaluación espaciotemporal de la cobertura vegetal del parque nacional Henri Pittier, Venezuela. GeoFocus, Revista Internacional de Ciencia y Tecnología de la Información Geográfica (Artículos), 28, 25-58. http://dx.doi.org/10.21138/GF.742

hileras significa que hubo ganancia de la unidad, o pérdidas, si se encuentran en las columnas (Berlanga et al., 2009).

De la matriz de detección de cambios se calculó el porcentaje del área de estudio sin cambio y un estimador del coeficiente de Kappa, pero que en este caso toma valores en el intervalo de -1.0 a +1.0. Los valores cercanos a -1.0 implican un cambio total, valores cercanos a cero denotan cambios próximos a $50 \%$ y valores cercanos a +1.0 indican ausencia de cambios (Eastman et al., 1995).

A fin de mejorar el análisis de los cambios de cobertura se obtuvieron, para cada clase, las medidas de estabilidad de localización $(E L)$ y estabilidad de residencia $(E R)$ definidas por Ramsey III et al. (2001) como:

Donde:

$$
\begin{gathered}
E L=[\mathrm{C} b-\mathrm{PC} b / \mathrm{C} b]^{*} 100 \\
E R=[\mathrm{C} f-\mathrm{C} b / \mathrm{C} b]^{*} 100
\end{gathered}
$$

$E L=$ Estabilidad de localización

$E R=$ Estabilidad de residencia

$C b=$ Cobertura en el año base

$P C b=$ Pérdida de cobertura en el año base

$C f=$ Cobertura final

La $E L$ se refiere al porcentaje de la clase de cobertura que permanece como la misma clase, en la misma localización de principio a fin del período estudiado. Por su parte, la $E R$ se refiere al porcentaje de cambio en cada clase con respecto al área de estudio durante el período evaluado.

Los valores cero asociados a una clase indican cambios netos nulos en su área de cobertura dentro del área total en el período evaluado. Los valores positivos muestran un incremento en la cobertura final $(C f)$ comparada con el año base $(C b)$. Los valores negativos, implican disminución en la cobertura comparada con el año base (Ramsey III, et al., 2001).

\section{Resultados}

4.1 Mapa de cobertura vegetal para cada año

El resultado obtenido del proceso de la clasificación supervisada, para cada año es un mapa en formato ráster que muestra las diferentes clases obtenidas, los cuales fueron vectorizados. En el caso del año 2014 (Figura 3), el valor del índice Kappa correspondió a 0.87, lo que es considerado muy bueno de acuerdo con la fuerza de concordancia. A su vez la exactitud total de la clasificación resulto ser de $90 \%$, indicando que la clasificación fue realizada correctamente (Tabla 4). 
Rebolledo López, D. C., y Lores Ochoa, D. C. (2021). Evaluación espaciotemporal de la cobertura vegetal del parque nacional Henri Pittier, Venezuela. GeoFocus, Revista Internacional de Ciencia y Tecnología de la Información Geográfica (Artículos), 28, 25-58. http://dx.doi.org/10.21138/GF.742

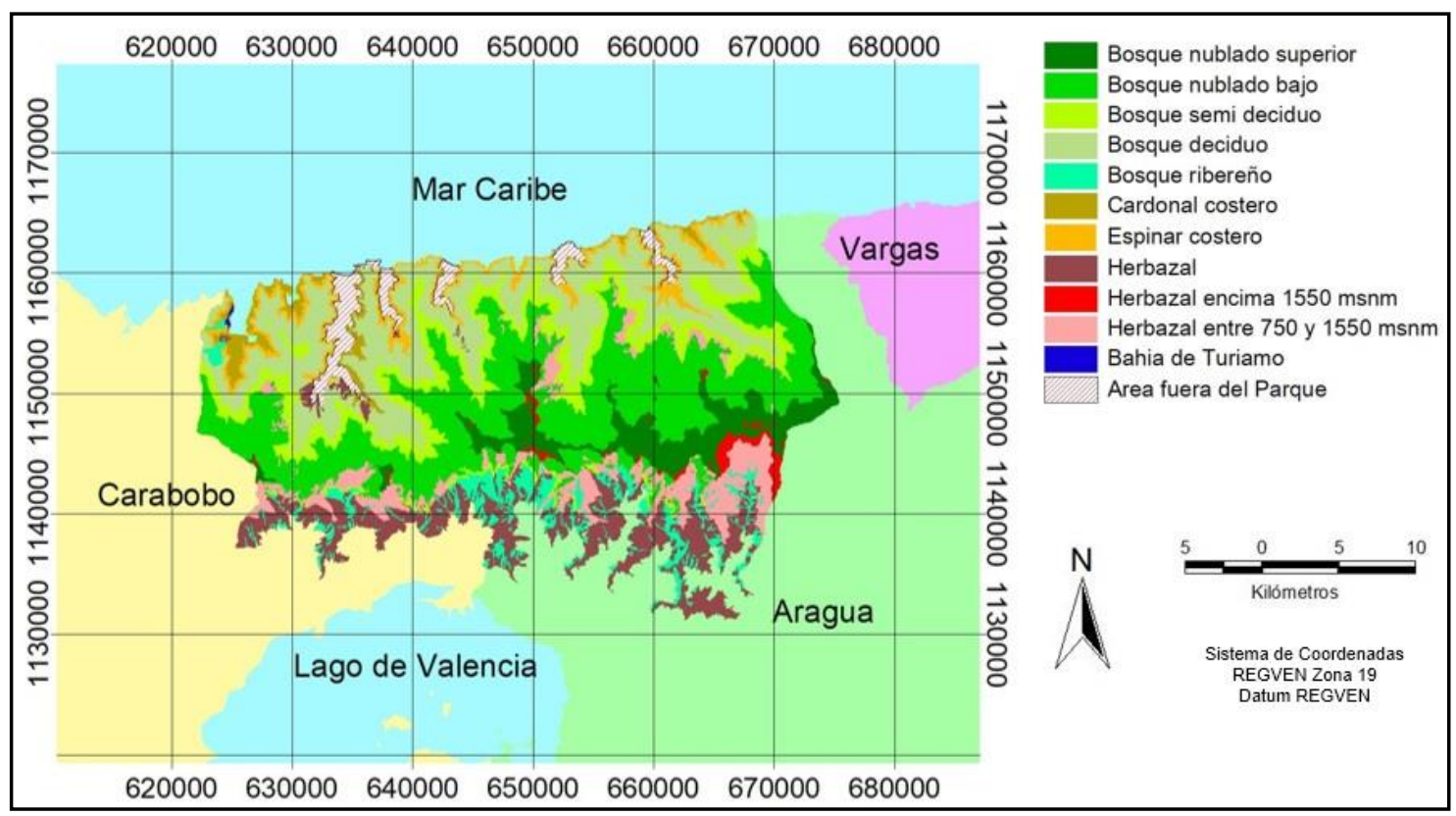

Figura 3. Mapa de cobertura vegetal año 2014.

Fuente: Elaboración propia.

Tabla 4. Matriz de confusión del mapa de cobertura vegetal 2014.

\begin{tabular}{|c|c|c|c|c|c|c|c|c|c|c|c|c|c|}
\hline \multirow{2}{*}{$\begin{array}{c}\text { Datos de } \\
\text { la } \\
\text { Clasificac. }\end{array}$} & \multicolumn{11}{|c|}{ Datos de Referencia } & \multirow{2}{*}{$\begin{array}{c}\text { Exactitud } \\
\text { Usuario } \\
\%\end{array}$} & \multirow{2}{*}{$\begin{array}{c}\text { Error } \\
\text { Comisión } \\
\%\end{array}$} \\
\hline & Bns & $\mathrm{Bnb}$ & Bsd & $\mathrm{Bd}$ & $\mathrm{Br}$ & $\mathrm{H}$ & $\mathrm{H}_{1550}$ & $\mathrm{H}_{750}$ & Ec & $\mathrm{Cc}$ & Total & & \\
\hline Bns & 741 & 4 & 0 & 0 & 0 & 0 & 0 & 0 & 0 & 0 & 745 & 99.46 & 0.54 \\
\hline $\mathrm{Bnb}$ & 0 & 1765 & 0 & 0 & 0 & 0 & 0 & 0 & 0 & 0 & 1765 & 100.00 & 0.00 \\
\hline Bsd & 0 & 0 & 9594 & 2 & 428 & 0 & 0 & 0 & 0 & 0 & 10024 & 95.71 & 4.29 \\
\hline $\mathrm{Bd}$ & 0 & 0 & 168 & 6128 & 65 & 0 & 0 & 4 & 118 & 84 & 6567 & 93,32 & 6,68 \\
\hline $\mathrm{Br}$ & 0 & 0 & 733 & 116 & 2510 & 0 & 0 & 7 & 0 & 0 & 3366 & 74.57 & 25.43 \\
\hline $\mathrm{H}$ & 0 & 0 & 0 & 0 & 0 & 4085 & 116 & 14 & 0 & 0 & 4215 & 96,92 & 3,08 \\
\hline $\mathrm{H}_{1550}$ & 0 & 0 & 0 & 0 & 1 & 146 & 1794 & 37 & 0 & 0 & 1978 & 90.70 & 9.30 \\
\hline $\mathrm{H}_{750}$ & 0 & 0 & 0 & 1 & 3 & 17 & 32 & 3400 & 0 & 6 & 3459 & 98.29 & 1,71 \\
\hline Ec & 0 & 0 & 0 & 636 & 7 & 0 & 0 & 0 & 1970 & 196 & 2809 & 70.13 & 29.87 \\
\hline $\mathrm{Cc}$ & 0 & 0 & 0 & 188 & 2 & 0 & 0 & 0 & 306 & 963 & 1459 & 66,00 & 34.00 \\
\hline Total & 741 & 1769 & 10495 & 7071 & 3016 & 4248 & 1942 & 3462 & 2394 & 1249 & 36387 & & \\
\hline $\begin{array}{l}\text { Exactitud } \\
\text { Productor } \\
\%\end{array}$ & 100 & 99,77 & 91,41 & 86,66 & 83,22 & 96,16 & 92,38 & 98,21 & 82,29 & 77,10 & & & \\
\hline $\begin{array}{l}\text { Error } \\
\text { Omisión } \\
\% \\
\end{array}$ & 0,00 & 0,23 & 8,59 & 13,34 & 16,78 & 3,84 & 7,62 & 1,79 & 17,71 & 22,90 & & & \\
\hline Exactitu & total $=$ & 90 & & & hdice $\mathrm{Ka}$ & $\mathrm{pa}=0,8$ & & & & & & & \\
\hline
\end{tabular}

Para el año 2018 (Figura 4), al igual que para el año 2014 el índice Kappa arrojó un valor de 0.87 , considerado muy bueno de acuerdo con la fuerza de concordancia. La exactitud total de la 


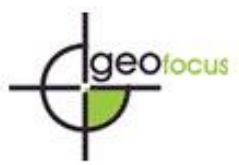

Rebolledo López, D. C., y Lores Ochoa, D. C. (2021). Evaluación espaciotemporal de la cobertura vegetal del parque nacional Henri Pittier, Venezuela. GeoFocus, Revista Internacional de Ciencia y Tecnología de la Información Geográfica (Artículos), 28, 25-58. http://dx.doi.org/10.21138/GF.742

clasificación dio $87 \%$, mostrando, de igual forma, que la clasificación fue realizada correctamente (Tabla 5).

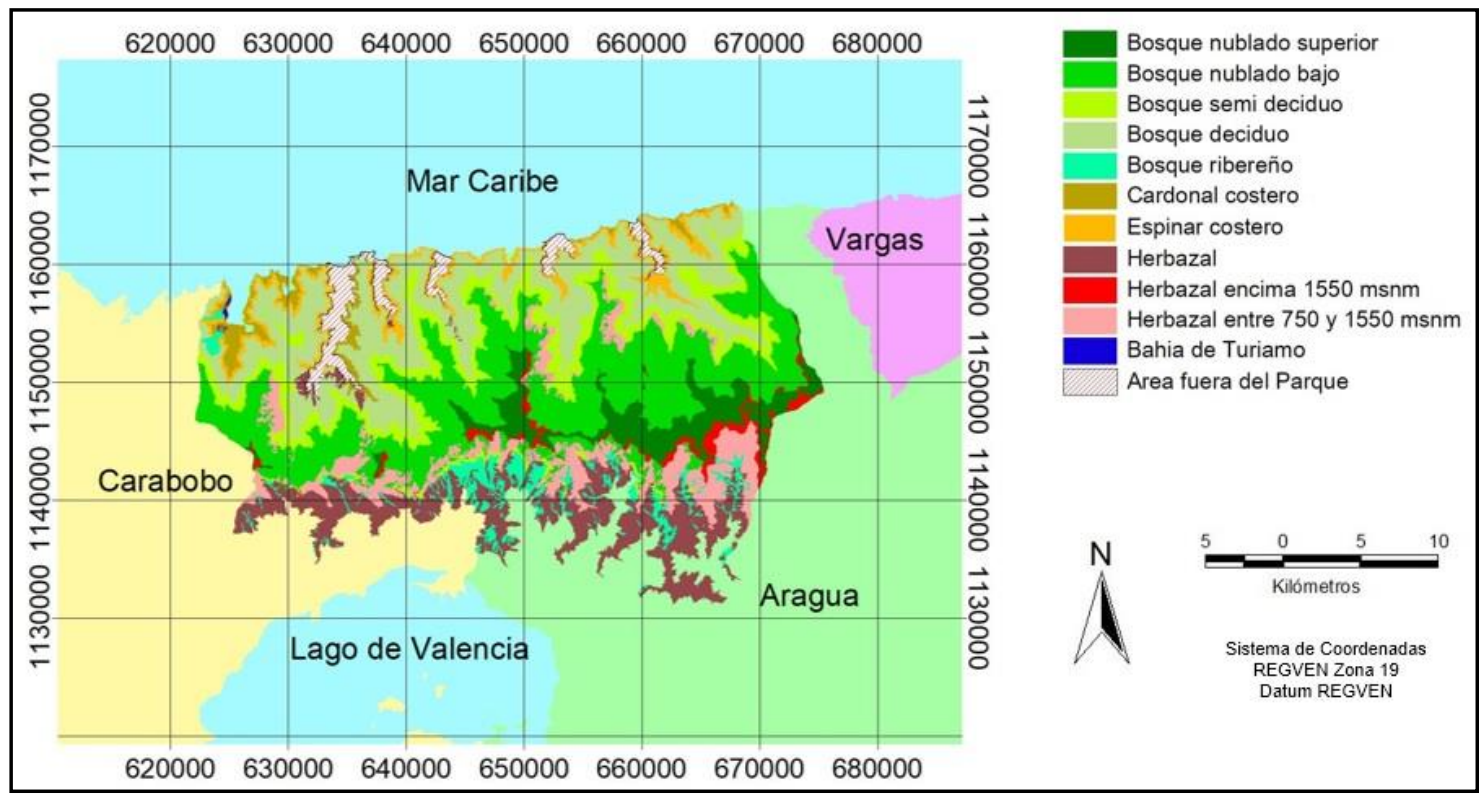

Figura 4. Mapa de cobertura vegetal año 2018.

Fuente: Elaboración propia.

Tabla 5. Matriz de confusión mapa de cobertura vegetal 2018.

\begin{tabular}{|c|c|c|c|c|c|c|c|c|c|c|c|c|c|}
\hline \multirow{2}{*}{$\begin{array}{c}\text { Datos de la } \\
\text { Clasificación }\end{array}$} & \multicolumn{11}{|c|}{ Datos de Referencia } & \multirow{2}{*}{$\begin{array}{c}\text { Exactitud } \\
\text { del } \\
\text { Usuario \% }\end{array}$} & \multirow{2}{*}{$\begin{array}{c}\text { Error por } \\
\text { Comisión } \\
\%\end{array}$} \\
\hline & Bns & Bnb & Bsd & $\mathrm{Bd}$ & $\mathrm{Br}$ & $\mathrm{H}$ & $\mathrm{H}_{1550}$ & $\mathrm{H}_{750}$ & Ec & $\mathrm{Cc}$ & Total & & \\
\hline Bns & 924 & 54 & 0 & 16 & 0 & 0 & 10 & 0 & 0 & 0 & 1004 & 92,03 & 7,97 \\
\hline Bnb & 25 & 1310 & 190 & 7 & 0 & 0 & 23 & 0 & 0 & 0 & 1555 & 84,24 & 15,76 \\
\hline Bsd & 0 & 147 & 1520 & 48 & 1 & 0 & 119 & 0 & 0 & 0 & 1835 & 82,83 & 17,17 \\
\hline $\mathrm{Bd}$ & 15 & 17 & 60 & 1515 & 4 & 0 & 31 & 0 & 0 & 18 & 1660 & 91,27 & 8,73 \\
\hline $\mathrm{Br}$ & 0 & 1 & 8 & 4 & 201 & 0 & 384 & 0 & 0 & 0 & 598 & 33,61 & 66,39 \\
\hline $\mathrm{H}$ & 0 & 0 & 0 & 0 & 0 & 156 & 0 & 0 & 0 & 20 & 176 & 88,64 & 11,36 \\
\hline $\mathrm{H}_{1550}$ & 2 & 16 & 36 & 2 & 84 & 0 & 1481 & 3 & 0 & 0 & 1624 & 91,19 & 8,81 \\
\hline $\mathrm{H}_{750}$ & 0 & 0 & 0 & 0 & 1 & 0 & 0 & 558 & 0 & 0 & 559 & 99,82 & 0,18 \\
\hline $\mathrm{Ec}$ & 0 & 0 & 0 & 0 & 0 & 0 & 0 & 0 & 587 & 20 & 607 & 96,71 & 3,29 \\
\hline $\mathrm{CC}$ & 0 & 0 & 0 & 1 & 0 & 7 & 0 & 0 & 4 & 893 & 905 & 98,67 & 1,33 \\
\hline Total & 966 & 1545 & 1814 & 1593 & 291 & 163 & 2048 & 561 & 591 & 951 & \begin{tabular}{|l|}
10523 \\
\end{tabular} & & \\
\hline $\begin{array}{l}\text { Exactitud del } \\
\text { Productor }\end{array}$ & 95,65 & 84,79 & 83,79 & 95,10 & 69,07 & 95,71 & 72,31 & 99,47 & 99,32 & 93,90 & & & \\
\hline $\begin{array}{l}\text { Error de } \\
\text { Omisión \% }\end{array}$ & 4,35 & 15,21 & 16,21 & 4,90 & 30,93 & 4,29 & 27,69 & 0,53 & 0,68 & 6,10 & & & \\
\hline Exactitud & total $=0$ & & & & ce de & $\mathrm{ppa}=$ & & & & & & & \\
\hline
\end{tabular}

Fuente: Elaboración propia. 


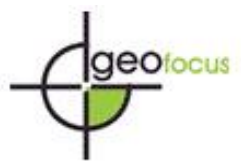

Rebolledo López, D. C., y Lores Ochoa, D. C. (2021). Evaluación espaciotemporal de la cobertura vegetal del parque nacional Henri Pittier, Venezuela. GeoFocus, Revista Internacional de Ciencia y Tecnología de la Información Geográfica (Artículos), 28, 25-58. http://dx.doi.org/10.21138/GF.742

\subsection{Análisis de la cobertura vegetal, período 2010-2014}

El análisis del cambio absoluto de las unidades de cobertura vegetal muestra que la mayoría de las coberturas presentaron variaciones en su superficie, excepto las coberturas de los Bsd y Br. Las coberturas que disminuyeron fueron: Bns (1238 ha), Bnb (2864 ha), Bd (34 ha) y Ec (654 ha). Las unidades de vegetación que presentaron un aumento fueron los herbazales: $\mathrm{H}$ aumentaron 27 ha, $\mathrm{H}_{750} 3354$ ha y $\mathrm{H}_{1550} 1155$ ha (Figura 5A). En la Figura 5B se observan las pérdidas y las ganancias de las coberturas vegetales. Los valores negativos (rojo) como pérdidas y los positivos (verde) como ganancias.

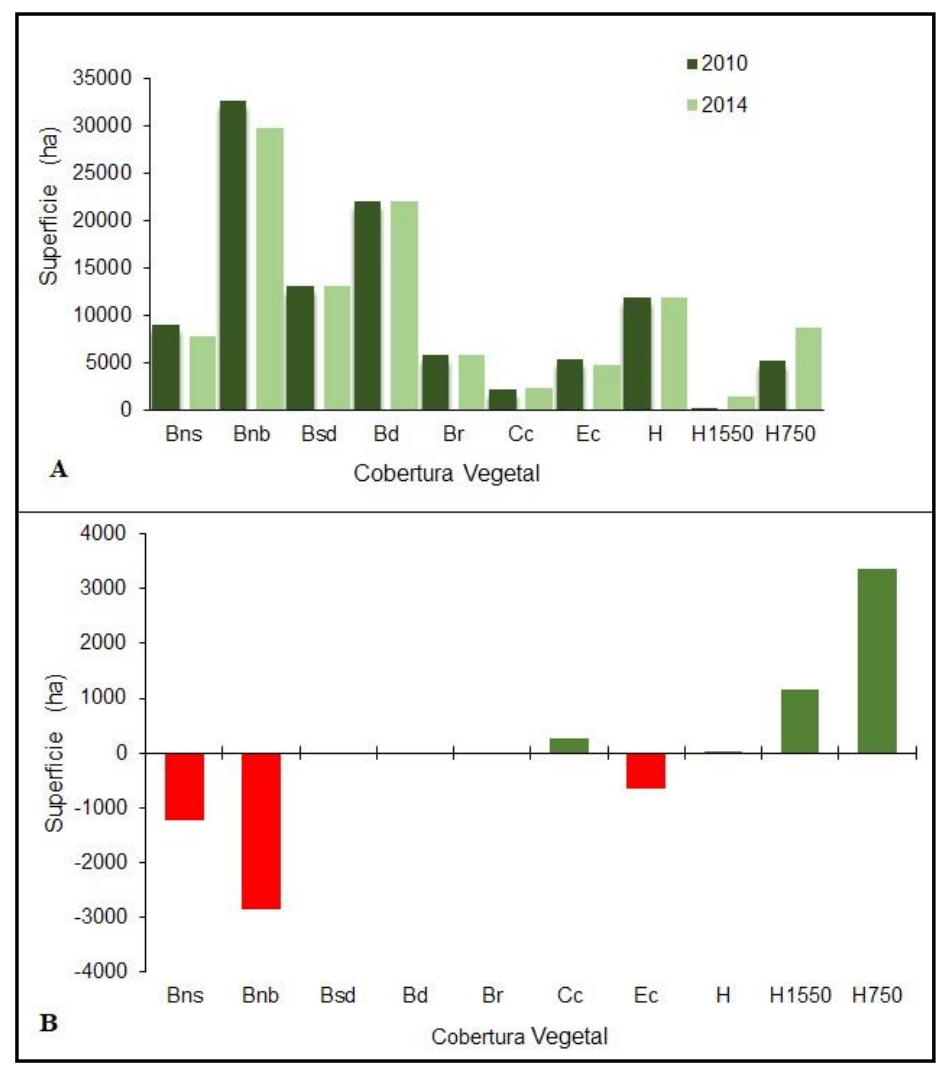

Figura 5. Cambio de la cobertura vegetal período 2010-2014: A) Coberturas; B) Cambios en la superficie de las coberturas (en rojo las pérdidas y en verde las ganancias). Fuente: Elaboración propia.

El balance de superficie que muestra la matriz de cambios para el período 2010-2014 facilita la medición del canje de superficie entre las diferentes clases de cobertura. El resultado muestra que el $95 \%$ de la cobertura vegetal del área analizada se mantuvo con las mismas unidades de vegetación que había para el año 2010 con un porcentaje de cambio total de 4,47 \% (4787 ha) (Tabla 7). 


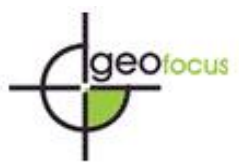

Rebolledo López, D. C., y Lores Ochoa, D. C. (2021). Evaluación espaciotemporal de la cobertura vegetal del parque nacional Henri Pittier, Venezuela. GeoFocus, Revista Internacional de Ciencia y Tecnología de la Información Geográfica (Artículos), 28, 25-58. http://dx.doi.org/10.21138/GF.742

De acuerdo con los valores de $E R$, las coberturas de los Bns, Bnb, Bd y Ec ( $E R=-13,74, E R$ $=-8,78, E R=-0,15$ y $E R=-12,26$, respectivamente) presentan tendencia a la disminución. Los Bsd y $\mathrm{Br}$ no sufrieron cambios $(E R=0)$. Los $\mathrm{H}$ muestran valores positivos de $E R$, lo que indica un incremento de su superficie en el año 2014 con respecto al 2010.

Tabla 7. Matriz de detección de cambios del período 2010-2014.

\begin{tabular}{|c|c|c|c|c|c|c|c|c|c|c|c|}
\hline \multirow[b]{2}{*}{$\begin{array}{c}\text { Cobertura } \\
2014\end{array}$} & \multicolumn{10}{|c|}{ Cobertura 2010} & \multirow[b]{2}{*}{$\begin{array}{l}\text { Total } \\
2014 \\
\end{array}$} \\
\hline & Bns & Bnb & Bsd & $\mathrm{Bd}$ & $\mathrm{Br}$ & $\mathrm{CC}$ & Ec & $\mathrm{H}$ & $\mathrm{H}_{1550}$ & $\mathrm{H}_{750}$ & \\
\hline Bns & 7772 & 0 & 0 & 0 & 0 & 0 & 0 & 0 & 0 & 0 & 7772 \\
\hline Bnb & 0 & 29749 & 0 & 0 & 0 & 0 & 0 & 0 & 0 & 0 & 29749 \\
\hline Bsd & 0 & 0 & 13040 & 0 & 0 & 0 & 0 & 0 & 0 & 0 & 13040 \\
\hline $\mathrm{Bd}$ & 0 & 0 & 0 & 21986 & 0 & 0 & 0 & 0 & 0 & 0 & 21986 \\
\hline $\mathrm{Br}$ & 0 & 0 & 0 & 0 & 5720 & 0 & 0 & 0 & 0 & 0 & 5720 \\
\hline $\mathrm{Cc}$ & 0 & 0 & 0 & 0 & 0 & 2096 & 254 & 0 & 0 & 0 & 2350 \\
\hline $\mathrm{Ec}$ & 0 & 0 & 0 & 0 & 0 & 0 & 4680 & 0 & 0 & 0 & 4680 \\
\hline $\mathrm{H}$ & 0 & 0 & 0 & 0 & 0 & 0 & 27 & 11833 & 0 & 0 & 11860 \\
\hline $\mathrm{H} 1_{550}$ & 1155 & 0 & 0 & 0 & 0 & 0 & 0 & 0 & 194 & 0 & 1349 \\
\hline $\mathrm{H}_{750}$ & 83 & 2864 & 0 & 34 & 0 & 0 & 373 & 0 & 0 & 5247 & 8601 \\
\hline Total $_{2010}$ & 9010 & 32613 & 13040 & 22020 & 5720 & 2096 & 5334 & 11833 & 194 & 5247 & 107107 \\
\hline$E L$ & 86,00 & 91,00 & 100,00 & 100,00 & 100,00 & 100,00 & 88,00 & 100,00 & 100,00 & 100,00 & \\
\hline$E R$ & $-13,74$ & $-8,78$ & 0,00 & $-0,15$ & 0,00 & 12,12 & $-12,26$ & 0,23 & 595,36 & 63,92 & \\
\hline \multicolumn{11}{|c|}{ Porcentaje de Cambio $=4,47$} & \\
\hline
\end{tabular}

Fuente: Elaboración propia.

\subsection{Análisis de la cobertura vegetal, período 2014-2018}

Las coberturas del PNHP durante el período 2014-2018 presentaron cambios o variaciones en sus superficies Las unidades de vegetación que disminuyeron fueron: Bns (809 ha), Bnb (1326 ha), Bsd (264 ha) y Br (1928 ha). El resto de las coberturas aumentaron su superficie, Bd (23 ha), Cc (464 ha), Ec (301 ha), H (1400 ha), $\mathrm{H}_{750}$ (1051 ha) y $\mathrm{H}_{1550}$ (888 ha). El Br fue la unidad que perdió más superficie y la que ganó más fue el H (Figura 6A). En la Figura 6B se observan las pérdidas y las ganancias de las coberturas vegetales. Los valores negativos (rojo) como pérdidas y los positivos (verde) como ganancias.

La matriz de detección de cambios para el período 2014-2018 refleja que $95 \%$ de la cobertura vegetal del área analizada se mantuvo igual respecto al año 2014, mientras que el porcentaje de cambio total fue de 4,04\% (4327 ha).

Los resultados de las $E R$ muestran que las coberturas con disminución de superficie fueron: el $\operatorname{Br}(E R=-33,71)$ seguido del Bns $(E R=-10 \%)$, el Bnb $(E R=-4,46 \%)$ y el Bsd $(E R=-2,02 \%)$. El resto de las unidades de vegetación $(\mathrm{Bd}, \mathrm{Cc}, \mathrm{Ec}$ y $\mathrm{H})$ presentaron valores positivos, lo que implica un incremento en la superficie de estas unidades de vegetación para el año 2018. La unidad que perdió mayor superficie en este período fue el Bnb y la que ganó más fue el $\mathrm{H}_{750}$. (Tabla 9). 


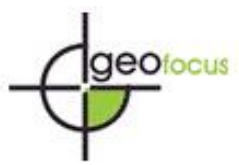

Rebolledo López, D. C., y Lores Ochoa, D. C. (2021). Evaluación espaciotemporal de la cobertura vegetal del parque nacional Henri Pittier, Venezuela. GeoFocus, Revista Internacional de Ciencia y Tecnología de la Información Geográfica (Artículos), 28, 25-58. http://dx.doi.org/10.21138/GF.742

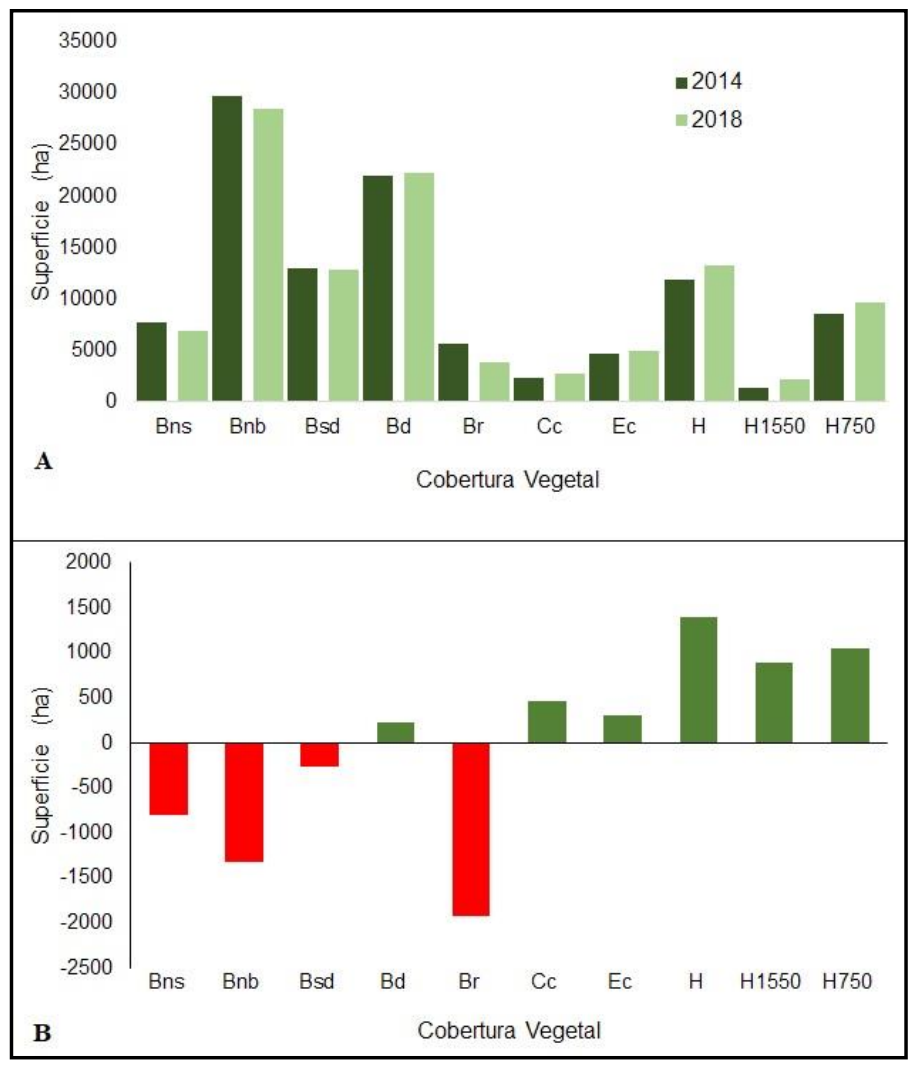

Figura 6. Cambio de la cobertura vegetal período 2014-2018: A) Coberturas; B) Cambios en la superficie de las coberturas (en rojo las pérdidas y en verde las ganancias). Fuente: Elaboración propia.

Tabla 9. Matriz de Detección de Cambio del período 2014-2018.

\begin{tabular}{|c|c|c|c|c|c|c|c|c|c|c|c|}
\hline \multirow{2}{*}{$\begin{array}{c}\text { Cobertura } \\
2018\end{array}$} & \multicolumn{10}{|c|}{ Cobertura 2014} & \multirow[t]{2}{*}{$\begin{array}{l}\text { Total } \\
2018 \\
\end{array}$} \\
\hline & Bns & Bnb & Bsd & $\mathrm{Bd}$ & $\mathrm{Br}$ & $\mathrm{CC}$ & Ec & $\mathrm{H}$ & $\mathrm{H}_{1550}$ & $\mathrm{H}_{750}$ & \\
\hline Bns & 6963 & 0 & 0 & 0 & 0 & 0 & 0 & 0 & 0 & 0 & 6963 \\
\hline Bnb & 0 & 28423 & 0 & 0 & 0 & 0 & 0 & 0 & 0 & 0 & 28423 \\
\hline Bsd & 0 & 0 & 12776 & 0 & 0 & 0 & 0 & 0 & 0 & 0 & 12776 \\
\hline $\mathrm{Bd}$ & 0 & 0 & 223 & 21986 & 0 & 0 & 0 & 0 & 0 & 0 & 22209 \\
\hline $\mathrm{Br}$ & 0 & 0 & 0 & 0 & 3792 & 0 & 0 & 0 & 0 & 0 & 3792 \\
\hline $\mathrm{Cc}$ & 0 & 0 & 0 & 0 & 464 & 2350 & 0 & 0 & 0 & 0 & 2814 \\
\hline $\mathrm{Ec}$ & 0 & 0 & 0 & 0 & 301 & 0 & 4680 & 0 & 0 & 0 & 4981 \\
\hline $\mathrm{H}$ & 0 & 196 & 41 & 0 & 1163 & 0 & 0 & 11860 & 0 & 0 & 13260 \\
\hline $\mathrm{H}_{1550}$ & 809 & 79 & 0 & 0 & 0 & 0 & 0 & 0 & 1349 & 0 & 2237 \\
\hline $\mathrm{H}_{750}$ & 0 & 1051 & 0 & & 0 & 0 & 0 & 0 & 0 & 8601 & 9652 \\
\hline Total $_{2014}$ & 7772 & 29749 & 13040 & 21986 & 5720 & 2350 & 4680 & 11860 & 1349 & 8601 & 107107 \\
\hline$E L$ & 90,00 & 96,00 & 98,00 & 100,00 & 66,00 & 100,00 & 100,00 & 100,00 & 100,00 & 100,00 & \\
\hline$E R$ & $-10,00$ & $-4,46$ & $-2,02$ & 1,01 & $-33,71$ & 19,74 & 6,43 & 11,80 & 65,83 & 12,22 & \\
\hline \multicolumn{3}{|c|}{ Exactitud $=0.95$} & & 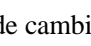 & & & & & & & \\
\hline
\end{tabular}

Fuente: Elaboración propia. 


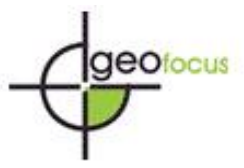

Rebolledo López, D. C., y Lores Ochoa, D. C. (2021). Evaluación espaciotemporal de la cobertura vegetal del parque nacional Henri Pittier, Venezuela. GeoFocus, Revista Internacional de Ciencia y Tecnología de la Información Geográfica (Artículos), 28, 25-58. http://dx.doi.org/10.21138/GF.742

\subsection{Análisis de la cobertura vegetal, período 2010-2018}

El análisis de la cobertura vegetal de los resultados de este período afirma la continua disminución de la cobertura boscosa del PNHP. Así se tiene que en el Bns la pérdida fue de 2047 ha y 4190 ha para el Bnb. El Br muestra una disminución significativa de su superficie con 1928 ha, le siguieron las coberturas del Ec (353 ha) y el Bsd (264 ha). El Bd y el Cc incrementaron solo en 189 ha $(\mathrm{Bd})$ y 718 ha $(\mathrm{Cc})$. Las coberturas vegetales que incrementaron su superficie en mayor magnitud siguen siendo los $\mathrm{H}$. Los $\mathrm{H}$ (427 ha), los $\mathrm{H}_{750}$ (4405 ha) y los $\mathrm{H}_{1550}$ (2043 ha) (Figura 7A). Las pérdidas (rojo) y las ganancias (verde) se ilustran en la Figura 7B.

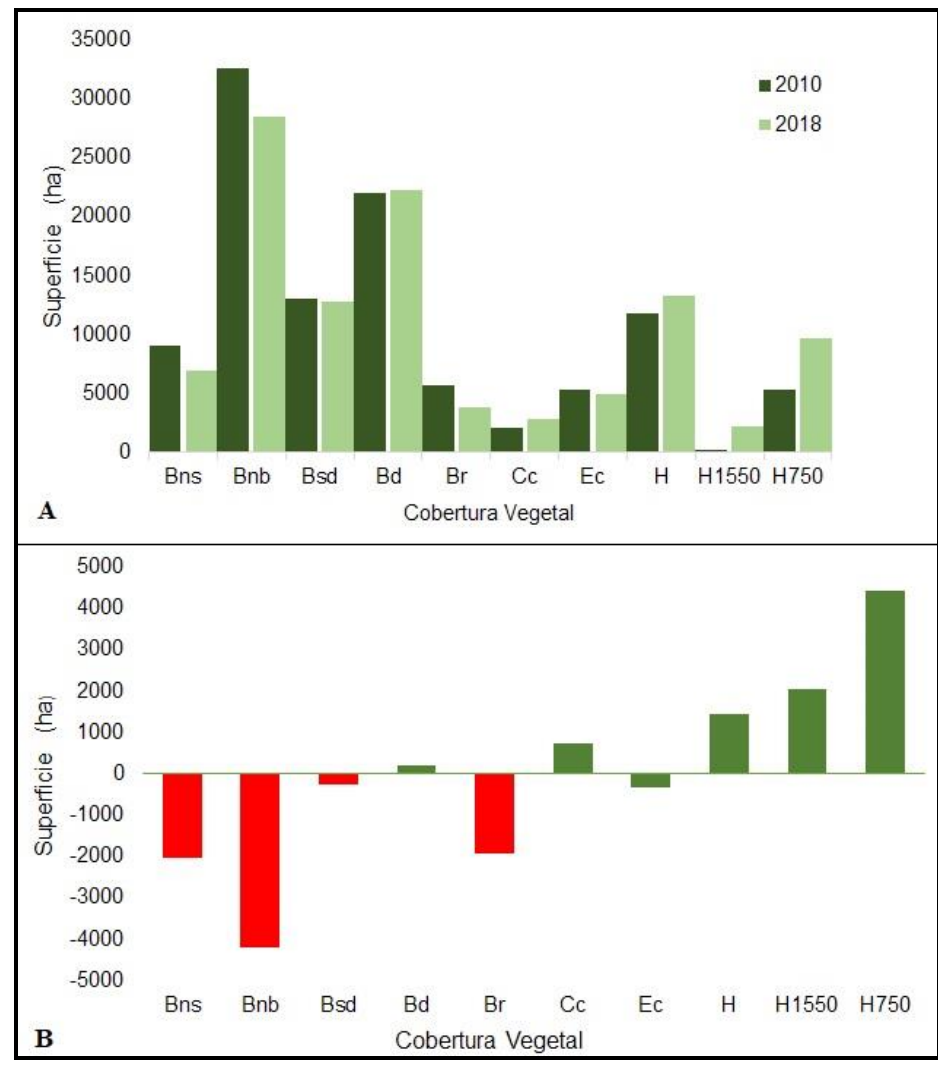

Figura 7. Cambio de la cobertura vegetal período 2010-2018: A) Coberturas; B) Cambios en la superficie de las coberturas (en rojo las pérdidas y en verde las ganancias).

Fuente: Elaboración propia. 


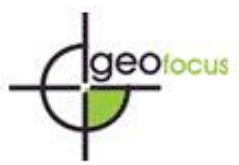

Rebolledo López, D. C., y Lores Ochoa, D. C. (2021). Evaluación espaciotemporal de la cobertura vegetal del parque nacional Henri Pittier, Venezuela. GeoFocus, Revista Internacional de Ciencia y Tecnología de la Información Geográfica (Artículos), 28, 25-58. http://dx.doi.org/10.21138/GF.742

La Matriz de Detección de Cambio (2010-2018) refleja que el 90 \% del paisaje no presentó variaciones de cobertura, con un porcentaje de cambio total de 8,20 \% (8782 ha). Además, muestra que las coberturas que disminuyeron en su superficie fueron: Bns $(E R=-23,72)$, Bnb $(E R=-$ $12,85)$, Bsd $(E R=-2,02)$ y Ec $(E R=-6,62)$. El resto de las unidades vegetales $\left(\mathrm{Bd}, \mathrm{Cc}, \mathrm{H}, \mathrm{H}_{750} \mathrm{y}\right.$ $\mathrm{H}_{1550}$ ) presentaron valores positivos de $E R$, lo que indica un aumento en su superficie. (Tabla 11).

Tabla 11. Matriz de detección de cambios del período 2010-2018.

\begin{tabular}{|c|c|c|c|c|c|c|c|c|c|c|c|}
\hline \multirow{2}{*}{$\begin{array}{c}\text { Cobertura } \\
2018\end{array}$} & \multicolumn{10}{|c|}{ Cobertura 2010} & \multirow{2}{*}{ Total 2018} \\
\hline & Bns & $\mathrm{Bnb}$ & Bsd & $\mathrm{Bd}$ & $\mathrm{Br}$ & $\mathrm{CC}$ & $\mathrm{Ec}$ & $\mathrm{H}$ & $\mathrm{H}_{1550}$ & $\mathrm{H}_{750}$ & \\
\hline Bns & 6963 & 0 & 0 & 0 & 0 & 0 & 0 & 0 & 0 & 0 & 6963 \\
\hline Bnb & 0 & 28423 & 0 & 0 & 0 & 0 & 0 & 0 & 0 & 0 & 28423 \\
\hline Bsd & 0 & 0 & 12776 & 0 & 0 & 0 & 0 & 0 & 0 & 0 & 12776 \\
\hline $\mathrm{Bd}$ & 0 & 0 & 53 & 22020 & 0 & 0 & 136 & 0 & 0 & 0 & 22209 \\
\hline $\mathrm{Br}$ & 0 & 0 & 0 & 0 & 3792 & 0 & 0 & 0 & 0 & 0 & 3792 \\
\hline $\mathrm{Cc}$ & 0 & 0 & 0 & 0 & 501 & 2096 & 217 & 0 & 0 & 0 & 2814 \\
\hline Ec & 0 & 0 & 0 & 0 & 0 & 0 & 4981 & 0 & 0 & 0 & 4981 \\
\hline $\mathrm{H}$ & 0 & 0 & 0 & 0 & 1427 & 0 & 0 & 11833 & 0 & 0 & 13260 \\
\hline $\mathrm{H}_{1550}$ & 2043 & 0 & 0 & 0 & 0 & 0 & 0 & 0 & 194 & 0 & 2237 \\
\hline $\mathrm{H}_{750}$ & 4 & 4190 & 211 & 0 & 0 & 0 & 0 & 0 & 0 & 5247 & 9652 \\
\hline Total 2010 & 9010 & 32613 & 13040 & 22020 & 5720 & 2096 & 5334 & 11833 & 194 & 5247 & 107107 \\
\hline EL & 77.28 & 87.15 & 97.98 & 100.00 & 66,29 & 100.00 & 93,38 & 100.00 & 100.00 & 100.00 & \\
\hline ER & $-23,72$ & $-12,85$ & $-2,02$ & 0,86 & 33,71 & 34,26 & $-6,62$ & 12,06 & 1053,09 & 83,95 & \\
\hline
\end{tabular}

Fuente: Elaboración propia.

A fin de una mejor visualización de los cambios de las coberturas vegetales durante los períodos analizados se presenta la Figura 8. El análisis de la dinámica de cambio durante este período indica que las coberturas de $\mathrm{Bns}$, $\mathrm{Bnb}$ y $\mathrm{Br}$ han experimentado un descenso en el tiempo. Las mayores pérdidas ocurrieron en los Bnb y Br. Las clases de $\mathrm{H}$ proyectan aumentos en su superficie; observándose que las mayores ganancias estuvieron en los $\mathrm{H}_{750}$. Entre tanto las clases $\mathrm{Bd}$, Bsd, Cc y Ec permanecieron casi constantes, experimentando pequeños aumentos en su superficie.

Las pérdidas de las superficies de los Bns, Bnb y $\mathrm{Br}$ posiblemente se deben a los contactos que tienen estas unidades con los usos del suelo que han sido identificados por Abarca y Quiroz (2005) como los usos de mayor riesgo. Estas unidades de uso son vías de penetración y áreas cubiertas de vegetación con propiedades favorables para la ignición (H y bosques caducifolios). Téngase en cuenta que las vías de penetración entran en contacto con todas las unidades de cobertura vegetal. 


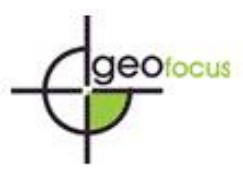

Rebolledo López, D. C., y Lores Ochoa, D. C. (2021). Evaluación espaciotemporal de la cobertura vegetal del parque nacional Henri Pittier, Venezuela. GeoFocus, Revista Internacional de Ciencia y Tecnología de la Información Geográfica (Artículos), 28, 25-58. http://dx.doi.org/10.21138/GF.742

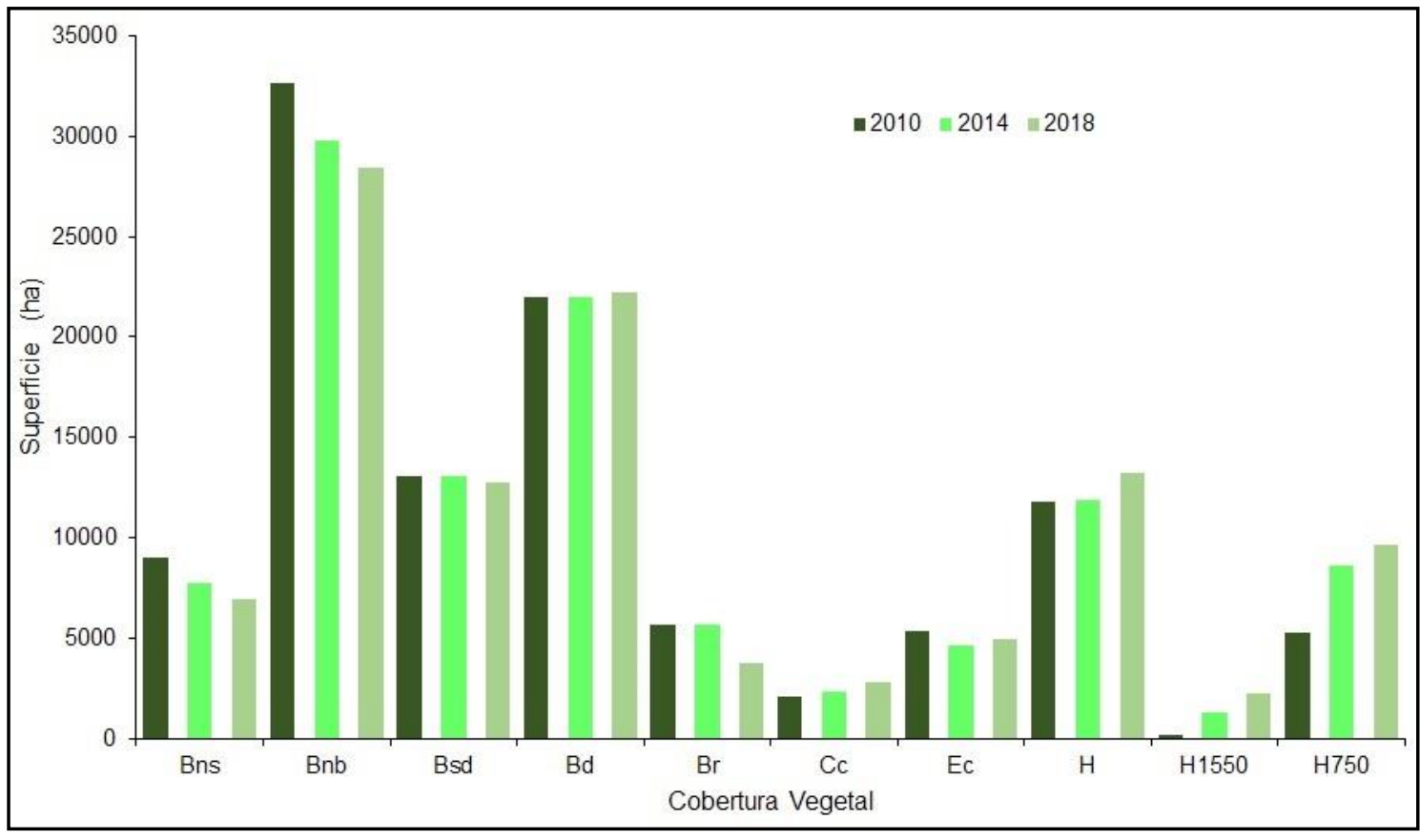

Figura 8. Tendencias de la cobertura vegetal.

Fuente: Elaboración propia

\section{Discusión}

Los Bn se ubican geográficamente entre las latitudes $23,5^{\circ}$ sur a $23,5^{\circ}$ norte. Estas unidades vegetales se desarrollan en espacios montañosos debido a la temperatura de la superficie del mar y sus corrientes, tamaño de sus montañas, orografía (Bruijnzeel \& Hamilton, 2001), orientación de las laderas o vertientes (Bruijnzeel \& Hamilton, 2001; Stadtmüler, 1986; Zinck, 1986), exposición a los vientos prevalecientes (Bruijnzeel \& Hamilton, 2001), factores topográficos locales (Ataroff, 2001; Bruijnzeel \& Hamilton, 2001; Zinck, 1986) y condiciones climáticas (Ataroff, 2001; Zinck, 1986) como gradientes de humedad (Bruijnzeel \& Hamilton, 2001; Zinck, 1986), precipitación horizontal u orográfica (Ataroff, 2001; Bruijnzeel \& Hamilton, 2001) y temperatura de la atmosfera (Ataroff, 2001; Bruijnzeel \& Hamilton, 2001; Zinck, 1986). Téngase en cuenta que la combinación entre ubicación geográfica, orientación de sus montañas, clima y sustrato del suelo se unen para potenciar las condiciones ideales para la generación de estas unidades de vegetación con su composición, estructura y microclima característico, considerados como ecosistemas únicos (Umaña et al., 2015).

Cabe resaltar que la presencia de los Bn en las grandes montañas ecuatoriales de La Tierra, presentan diferencias de acuerdo a las características que arriba se listaron, y a su vez, en función de su ubicación en el continente ya sea que estén vecinos al mar, o no (Stadtmüler, 1986). Así Bruijnzeel y Hamilton (2001) señalan que en el interior de los continentes y alejado del mar los Bn ocurren usualmente a una altitud entre 1200 hasta $1500 \mathrm{msnm}$; y en montañas pequeñas de islas (cercanos a la línea de la costa del mar), pueden estar en altitudes menores a $500 \mathrm{msnm}$. Ataroff y Rada (2000) señalaron que si estas unidades de vegetación están cerca del mar Caribe se ubican 


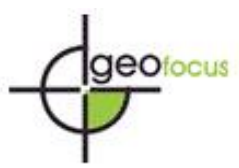

Rebolledo López, D. C., y Lores Ochoa, D. C. (2021). Evaluación espaciotemporal de la cobertura vegetal del parque nacional Henri Pittier, Venezuela. GeoFocus, Revista Internacional de Ciencia y Tecnología de la Información Geográfica (Artículos), 28, 25-58. http://dx.doi.org/10.21138/GF.742

entre 500 a $600 \mathrm{msnm}$, en las islas entre 1000 a 1500 . Dentro de los continentes entre 1700 a 3500 como en los Andes al oeste entre Colombia y Ecuador, por encima de 4000 al este entre Ecuador y Bolivia, al sur desde 1000 a 1500 hasta 2500 msnm, en Bolivia al norte de Argentina. En Honduras en las tierras continentales se han identificado entre 2000 hasta $3500 \mathrm{msnm}$ y en las áreas cercanas al mar entre 400 y $600 \mathrm{msnm}$ (Dudley \& Stolton, 2003). En Venezuela algunos autores los han descrito en las montañas circunvecinas al mar, entre 1000 y $2000 \mathrm{msnm}$; mientras que en áreas alejadas del mar entre 2000 a 3000 msnm (Bruijnzeel \& Hamilton, 2001; Zinck, 1986). Ataroff y Rada (2000), para los Andes venezolanos, los ubican entre 1700 a 3000 msnm. En el PNHP Zinck (1986) los identifican entre 900 msnm y 1800 msnm. Cardozo (1999) para el mismo PNHP, lo sitúa desde los $750 \mathrm{msnm}$ en la vertiente norte y en la vertiente sur, desde los $1000 \mathrm{msnm}$.

El PNHP presenta el escalonamiento bioclimático de los Bn reconocido por Zinck (1986), referido a la existencia de la secuencia de unidades vegetales constituidas desde los niveles más bajos por $\mathrm{Cc}, \mathrm{Ec}$ en la vertiente norte y de $\mathrm{H}$ en la sur, siguiendo a éstos se ubican los bosques en general y con ritmos estacionales crecientes hacia las altas altitudes. Así, las unidades de cobertura vegetal en la vertiente sur están constituidas desde $\mathrm{H}$ pasando por Bd, Bsd, Bnb y Bns. En cambio, al ascender por la vertiente norte se van presentando $\mathrm{Cc}, \mathrm{Ec}, \mathrm{Bd}, \mathrm{Bs}$, Bnb y Bns, y en ambas vertientes, asociados a los cursos de los ríos se visualizan los $\mathrm{Br}$. En ambas vertientes, de igual forma y gracias a las vías y senderos, es sencillo el contacto humano con estas unidades de vegetación. Situación poco común en la mayoría de los Bn del mundo (Bruijnzeel \& Hamilton, 2001).

En el PNHP las diferencias de las coberturas vegetales entre vertientes se sustentan en las características de los vientos Alisios, su encuentro con las montañas y la Convergencia Intertropical. Cuando estos vientos se enfrentan a la vertiente norte, vienen cargados de humedad del mar Caribe, y al toparse con este sistema de montaña, su carga de agua la van dejando en la biomasa vegetal mientras suben por los diversos pisos altitudinales, estratos y especies florales. Así, al atravesar la parte más alta de la montaña, estos vientos llegan con menos humedad y al bajar por la vertiente sur se encuentra con vientos cálidos y secos de la Convergencia Intertropical que ya han atravesado tanto el Lago de Valencia como la ciudad de Maracay. Téngase en cuenta que, mientras el aire sea más húmedo (Alisios), más rápidamente se condensará al ser enfriado y ascenderá sobre las laderas, y el punto de condensación es alcanzado más rápidamente por el aire frío que por el aire caliente (Bruijnzeel \& Hamilton, 2001). Es así como la formación de nubes del Bn, está determinada por el contenido de humedad y la temperatura de la atmósfera (Zinck, 1986). Esto posiblemente es lo que explica las diferentes alturas a las que aparecen los $\mathrm{Bn}$ en cada vertiente del PNHP.

\section{Algunos aspectos ecológicos}

Los $\mathrm{Bn}$ dentro de las coberturas vegetales muestran diferenciaciones de acuerdo a las condiciones geográficas como: altitud, precipitación, temperatura y presencia de neblina, y en cuanto a la cobertura vegetal, de acuerdo a número de estratos, composición, procesos ecológicos, relación entre las unidades de vegetación vecinas con sus respectivas especies vegetales predominantes, composición florística y sustrato (Bruijnzeel \& Hamilton, 2001; Stadtmüller, 1986). Estas combinaciones ofrecen condiciones para el desarrollo de diversas especies a diferentes 


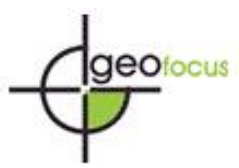

Rebolledo López, D. C., y Lores Ochoa, D. C. (2021). Evaluación espaciotemporal de la cobertura vegetal del parque nacional Henri Pittier, Venezuela. GeoFocus, Revista Internacional de Ciencia y Tecnología de la Información Geográfica (Artículos), 28, 25-58. http://dx.doi.org/10.21138/GF.742

alturas. Ejemplo de esto fue lo reportado por Ataroff (2001), Bruijnzeel y Hamilton (2001), Huber (1986) y Cardozo (1999). Así se tiene que, para el mundo Bruijnzeel y Hamilton (2001) diferenciaron cinco estratos de bosques. Éstos fueron: bosque de neblina enano, (de hadas o 'elfin'), Bn subalpino, Bn montano alto, Bn montano bajo y bosque montano bajo. Así mismo Beard (1944, 1955, citado por Stadtmüller, 1986) también diferenció cuatro tipos de Bn (bosque lluvioso montano bajo, bosque lluvioso montano, matorral montañoso y bosques de hadas); para Venezuela Ataroff (2001) ha diferenciado 13 tipos de Bn ubicados por encima de $500 \mathrm{msnm}$. Para el PNHP Huber (1986) reconoció tres tipos (transición, propiamente dicha y superior) y Cardozo (1999) registró dos (bajo y superior); clasificación usada en este estudio. Aunque según Ataroff (2001), estas diferencias se deben a la ausencia de un criterio único para denominar estos ecosistemas, y afirma que estas diferenciaciones lo que hacen es generar confusión, al momento de analizarlos y compararlos.

De igual manera, Bruijnzeel y Hamilton (2001) identificaron la cobertura vegetal del Bn montano bajo como el $\mathrm{Bn}$ con la mayor presencia de neblina y contenido de humedad, musgo y briofitas, reconocidos por el contenido de la mayor riqueza de especies vegetales. A su vez es equivalente al Bn propiamente dicho de Huber (1976) y al Bnb de Cardozo (1999), así como el Bnb de este estudio. También, este bosque fue reconocido por Zinck (1986) como el bosque más propenso a los movimientos de masas y a la generación de desastres. Alineado a lo anterior, en la Figura 4 se observa que las unidades de vegetación Bd, Bsd y Bnb de la vertiente sur son las unidades de bosques que poseen mayor superficie de contacto con los $\mathrm{H}$ y entre las tres unidades de vegetación los Bnb son los que tienen aún más superficies de contactos con los $\mathrm{H}$, y por ende están más expuestos a ser quemados. Esto se sustenta en la investigación de Abarca y Quiroz (2005) y se ratifica con los resultados de este estudio. Es decir, dentro del PNHP el Bnb es el bosque más vulnerable a ser destruido. En el período estudiado (2010-2018), al analizar las superficies perdidas de los bosques, se identifica que el Bnb presentó la mayor pérdida de cobertura vegetal (4190 ha). Esta pérdida constituye $41.90 \%$ de la superficie de bosque perdido durante el período de 20102018 , le sigue en orden decreciente el Bns (24.29 \%), el Br (22.87\%) y el Bsd (3.13\%).

La diversidad biológica de ecosistemas, especies y genes del PNHP, junto al almacenaje de carbono orgánico de la biomasa arbórea, y de la hojarasca, captura de agua de las niebla o lluvia orográfica son los servicios ecosistémicos aprovechables tanto a nivel local, regional, nacional y global. El Bn es muy importante por ser un reservorio genético dotado de una alta diversidad de especies, frecuentemente endémicas (Stadtmüller, 1986; Zinck, 1986). De igual manera, ofrece un potencial muy variado de resinas, maderas, fibras y plantas medicinales (Zinck. 1986; Rebolledo, 2014). Como lo expresa Verea y Díaz (2005) y Verea et al., (2000) el gradiente de montaña del PNHP dado por los pisos altitudinales producen uno de los mosaicos ambientales más complejos del país, con ambientes tan áridos como Cc y Ec en su parte más baja de la vertiente norte, pasando por los $\mathrm{Bd}$ y Bsd con ciclos anuales de lluvia y sequía marcadamente contrastantes, que luego se adentran en los Bn.

Esta enorme diversidad de ecosistemas genera condiciones para que este parque sea uno de los puntos claves para el desarrollo de investigaciones ornitológicas del país, pues en él se han registrado hasta la fecha 616 especies de aves que representan $45 \%$ de la avifauna total de Venezuela, estimada en 1381 especies (Verea \& Díaz, 2005). La diversidad de aves presentes en el 


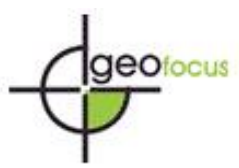

Rebolledo López, D. C., y Lores Ochoa, D. C. (2021). Evaluación espaciotemporal de la cobertura vegetal del parque nacional Henri Pittier, Venezuela. GeoFocus, Revista Internacional de Ciencia y Tecnología de la Información Geográfica (Artículos), 28, 25-58. http://dx.doi.org/10.21138/GF.742

PNHP lo reconoce como una de las áreas con mayor diversidad de aves del mundo y ésta está constituida tanto por especies residentes como migratorias (Lentino, 1990). Esta enorme diversidad de aves se encuentra distribuida a lo largo del gradiente generado por los pisos altitudinales del parque y genera uno de los ecosistemas más complejos del país (Fernández, 1997) como también lo identificaron Verea y Díaz (2005).

Complementando lo expresado en los párrafos anteriores, el hecho de que en pequeñas áreas del mismo $\mathrm{Bn}$ se evidencien la presencia de riqueza de nichos y de especies, lo convierte en una unidad vegetal muy vulnerable. Esto implica que en una determinada superficie existan pocos individuos de una misma especie y la sobreexplotación o destrucción de alguna de éstas, lo que conduciría a la extinción local (Zinck, 1986). Los Bn contienen concentraciones excepcionales de la biodiversidad mundial. Por ejemplo, los bosques montanos del Monte Kinabalu-Malasia albergan más de 1000 especies de orquídeas y más de 600 especies de helechos. En México los Bn cubren menos de $1 \%$ del país, aun así, en estas áreas se han reconocido la presencia de $12 \%$ de su flora, más de 3000 especies de plantas y, simultáneamente, el $30 \%$ de estas plantas son especies únicas (Aldrich \& Hostettler, 2000).

En consecuencia, el Bn a su vez es considerado como uno de los ecosistemas más ricos del mundo (Bruijnzeel \& Hamilton, 2001; Stadtmüller, 1986). Los Bn no solo son importantes por su cobertura vegetal, otro elemento de importancia es el suelo o medio edáfico. Ambos, suelo y cobertura vegetal constituyen un binomio esencial por sus relaciones estrechas y reciprocas: el suelo como soporte de la vegetación, la vegetación como protección del suelo; el suelo como filtro regulador de las aguas interceptadas por la vegetación, la vegetación como elemento activo de reciclaje de nutrientes en el suelo; etc. Por lo anterior, el piso altitudinal del Bn debe ser considerado como un medio particularmente vulnerable donde las intervenciones humanas deben ser estrictamente controladas (Zinck 1986).

La importancia de identificar los cambios de unidades de cobertura vegetal del PNHP causadas por incendios es porque éstos están destruyendo y modificando las coberturas del parque, como lo reporta este estudio. Por lo cual, paralelamente se están destruyendo mucho nichos y sus especies, aunque se crea que son pequeñas áreas. Además, las quemas, tanto de la cobertura vegetal como de la hojarasca, liberan $\mathrm{CO}_{2}$ a la atmosfera. El cambio de bosques a $\mathrm{H}$ es una pérdida de servicios ecosistémicos tanto a nivel local como regional, nacional y global. Porque, al no disponer de estas unidades de vegetación, la sociedad ya no dispondrá de los servicios ambientales perdidos por la merma de las coberturas vegetales Bns, Bnb, Bsd, Bd y Br. A la par, en las áreas de bosques degradados por su cercanía con los incendios posiblemente se esté dando lo identificado por Martin (2008); cuando afirma que los bosques degradados reducen su capacidad de producir bienes y servicios y también se puede estar generando el reconocido efecto borde (Cochrane, 2001; 2003; Cochrane \& Laurance, 2002; 2003).

En el PNHP, a causa de los incendios de vegetación, se estaría perdiendo diversidad biológica para siempre porque la diversidad biológica de un bosque destruida por un incendio es una pérdida irremplazable. Como lo reportaron Andrade et al., (2019) en un estudio en el cual monitorizaron escorrentía superficial, humedad edáfica, transporte de sedimentos, biomasa herbácea y radicular debido a alteraciones de los servicios ambientales de un bosque tropical seco. Éstos 


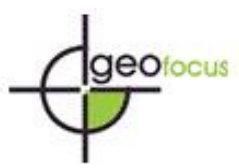

Rebolledo López, D. C., y Lores Ochoa, D. C. (2021). Evaluación espaciotemporal de la cobertura vegetal del parque nacional Henri Pittier, Venezuela. GeoFocus, Revista Internacional de Ciencia y Tecnología de la Información Geográfica (Artículos), 28, 25-58. http://dx.doi.org/10.21138/GF.742

encontraron que al disminuir la cobertura vegetal y ésta al convertirse en $\mathrm{H}$ aumenta la escorrentía superficial y producción de sedimentos porque la disponibilidad de biomasa genera mayores barreras al escurrimiento y se posibilita una mayor retención de agua en el suelo que maximiza la producción de biomasa.

\section{Hidrografía de los Bn}

A nivel local, el servicio más reconocido de los Bn ha sido el de preservación de las cualidades hidrológicas, porque éstos atrapan agua de la niebla o neblina y protegen o conservan las cuencas hidrográficas (Ataroff \& Rada, 2000; Bruijnzeel \& Hamilton, 2001; Zinck, 1986); este servicio está potencializado por la composición y estructura de la vegetación. La densa cobertura vegetal facilita la penetración del agua al suelo y evita que éste se erosione. Esto contribuye a asegurar el flujo de agua de manera continua por sus cuencas y cursos de ríos (Zinck, 1986), siendo el proceso ecológico que garantiza el suministro de agua, ya sea para consumo directo como agua potable o como para actividades de recreo y económicas como la agricultura de gran escala, turismo, hidroeléctrica, navegación, investigación, entre otras (Abarca \& Quiroz, 2005; Aldrich \& Hostettler, 2000; Rebolledo, 2014; Umaña et al., 2015).

El Bn constituye una malla fundamental del ciclo hidrológico porque es el piso altitudinal más abundantemente abastecido en aguas de lluvia (precipitación vertical) y de la niebla o neblina (precipitación horizontal u orográficas), unido al hecho de que estas aguas son filtradas por la cobertura vegetal y la hojarasca, antes de drenar a los ríos y recargan los acuíferos (Ataroff \& Rada, 2000; Zinck, 1986). El agua adicional que proviene de las nubes ha sido cuantificada entre $15 \%$ hasta $20 \%$ de la precipitación ordinaria, y en algunos lugares puede alcanzar entre $50 \%$ hasta $60 \%$. Esta función clave de los Bn como proveedores de agua dulce y barreras de seguridad contra la erosión del suelo está siendo cada vez más reconocida.

Ataroff y Rada (2000) analizaron un Bn en los Andes venezolanos y encontraron que el aporte de agua por la precipitación horizontal a este ecosistema fue de $9 \%$. Stadtmüller (1986) reportó evidencias sobre el porcentaje de precipitación orográfica de varios Bn del mundo tales como: Montaña de Loquillo-Puerto Rico (7.2 \% a 8.6 \%), Sierra Madre-México (14.0 \% -102.9 \%), Campos de Kulani, Kulani Mauka, Mauna Loa, Honoaila y Honulalai-Hawai (25.0-158.5 \%) y pendientes del Atlántico (15.3\%). Asimismo, en un estudio en los Andes colombiano Umaña et al. (2015) mediante el uso de dos técnicas para atrapar las nieblas reportaron valores entre $30.0 \%$ y $230.0 \%$, manifestando lo difícil e impreciso de estas mediciones, lo cual puede ser el motivo de la diversidad de los valores reportados por las diferentes fuentes.

Por otra parte, el servicio de agua potable y de recreo se ha registrado en especial cuando estos bosques se encuentran en áreas cercanas a centros poblados (Bruijnzeel \& Hamilton, 2001; Zinck, 1986) y muchas de las áreas protegidas de Venezuela están sustentadas en esta premisa (Naveda, 2015) así como en México, USA, Brasil, España, India, entre otros (Unión Mundial para la Naturaleza (IUCN), 2001). Millones de personas dependen del agua dulce que fluye de los Bn. Para ilustrar esto se han reconocido el Bn del Parque Nacional La Tigra (23,871 ha) en Honduras. Éste proporciona más de $40 \%$ del suministro anual de agua para 850000 personas de la ciudad capital (Dudley \& Sue, 2003). En Dar es Salaam, capital de Tanzania, 2,5 millones de personas se 


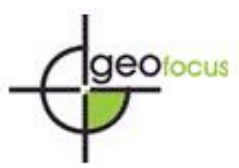

Rebolledo López, D. C., y Lores Ochoa, D. C. (2021). Evaluación espaciotemporal de la cobertura vegetal del parque nacional Henri Pittier, Venezuela. GeoFocus, Revista Internacional de Ciencia y Tecnología de la Información Geográfica (Artículos), 28, 25-58. http://dx.doi.org/10.21138/GF.742

benefician del agua que viene de las montañas Uluguru. Esta agua es aprovechada tanto para beber como para obtener hidroelectricidad. El agua proviene de los $\mathrm{Bn}$ de las montañas de Udzungwa. Otras capitales provistas por el agua de Bn son Quito (Ecuador), la cual beneficia a 1,3 millones de personas, y 20 millones de personas en Ciudad de México. Así como la montaña Celaque con más de nueve ríos en el norte de Honduras (Aldrich \& Hostettler, 2000).

La Reserva de la Biosfera de Sierra de las Minas-Guatemala con más de 60 ríos permanentes es el recurso de agua más grande de este país. Así mismo en áreas áridas y semiáridas, los parches de Bn son aún más cruciales para la provisión de agua de las comunidades circundantes, especialmente durante la época seca, como por ejemplo el Bn del Monte Kenya. Cabe destacar, que no existiría el Canal de Panamá sin Bn, sin el río Chagres. De hecho, la construcción del Canal de Panamá hubiera sido casi imposible: sus nacientes están arriba en la alta cuenca, en una serie de montañas tapizadas de Bn. Este ecosistema asegura la provisión de agua para los lagos Madden y Gatún, que brindan el agua suficiente para el calado necesario para los barcos en tránsito por el canal (Aldrich \& Hostettler, 2000).

En el caso del PNHP el suministro de agua a centros poblados es un servicio de vital importancia porque los ríos que drenan en las cuencas hidrográficas o son las únicas fuentes de agua dulce para consumo humano como en los casos de las poblaciones que lindan con la vertiente norte (Turiamo, La Ciénaga de Ocumare, Ocumare de la Costa de Oro, Cata, Cuyagua, Choroní, Chuao, Cepe, Puerto Maya, Tuja) o complementarios (Rebolledo, 2014). Los ríos de la vertiente sur son complementarios del sistema de agua potable de los centros poblados vecinos del PNHP como Cura, Aguas Caliente, Mariara del estado Carabobo y las ciudades de Maracay del estado Aragua (Abarca y Rodríguez, 2005; Rebolledo, 2014) y Turmero (Rebolledo, 2014).

Ataroff y Rada (2000) cuantificaron la pérdida de este servicio ecosistémico en un área andina de Venezuela y encontraron que los Bn fueron sustituidos por una gramínea (pastos kikuye, Pennisetum clandestinum). Este cambio de cobertura vegetal produjo un impacto desfavorable para el flujo de agua porque la estructura del bosque es más compleja que la del pastizal (herbazal). Las diferencias identificadas fueron las siguientes: los Bn aportan el equivalente a un mes de lluvia, la transpiración estimada es cuatro veces mayor en el pastizal que en el Bn, la precipitación horizontal es mayor en los Bn que en los pastizales, el flujo sub-superficial en los Bn es mucho mayor que en el pastizal, entre otras. Por lo anterior, la gran preocupación y llamado de atención a los tomadores de decisiones es que la conversión de bosques a $\mathrm{H}$ por incendios o quemas trae como consecuencia pérdidas de los servicios ambientales. Esta se convierte, en lo local, en una acción que impacta de manera directa los flujos de agua de los cuerpos de agua y las recargas de las aguas subterráneas.

De cualquier manera, es esencial proteger y mantener los $\mathrm{Bn}$ en sus condiciones naturales porque estas unidades de vegetación entre sus procesos y funciones ecológicas están la regulación del régimen de los ríos y el control de las inundaciones de las tierras bajas. Zinck (1986) afirma que la preservación de los $\mathrm{Bn}$ como reservas hidrológicas debería constituir una necesidad vital y corresponder a una estrategia prioritaria de la ordenación del territorio. Es importante de igual manera precisar que el servicio de protección de las cuencas generalmente se le ha reconocido en situaciones de precipitaciones típicas. 


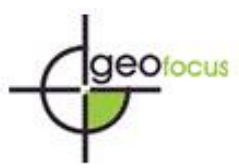

Rebolledo López, D. C., y Lores Ochoa, D. C. (2021). Evaluación espaciotemporal de la cobertura vegetal del parque nacional Henri Pittier, Venezuela. GeoFocus, Revista Internacional de Ciencia y Tecnología de la Información Geográfica (Artículos), 28, 25-58. http://dx.doi.org/10.21138/GF.742

Por lo contrario, en situaciones de precipitaciones atípicas de intensidad altamente excepcional como las ocurridas el 06/09/1987 (precipitación de $180 \mathrm{~mm}$, concentrada en menos de seis horas) en la cuenca del río El Limón del PNHP ubicada al norte de la ciudad de Maracay, Venezuela. Ésta fue acompañada de un alud torrencial de gran magnitud y consecuencias catastróficas dadas las condiciones de suelos. Se dieron varias avalanchas de tierra, peñas y troncos de árboles provocadas por denudaciones muy localizadas en laderas abiertas de suelos residuales granulares con pendientes elevadas (Audemard \& Singer, 2002). Este evento validó lo que ya había deducido Zinck (1986) y habían reafirmado Ríos et al. (2010): que los suelos del parque tienen un índice plástico bajo, susceptible de pasar de estado plástico a líquido al agregar porciones reducidas de agua. Lo cual significa que el suelo pudiera pasar del estado sólido al estado líquido con poca cantidad de agua, porque a su vez por su discontinuidad mecánica, tienen horizontes muy susceptibles a los movimientos solifluidales.

\section{Incendios en los Bn}

La diferencia de ubicación entre los Bn de la vertiente norte y la sur, es de 250 metros. Esta diferencia se explica por el comportamiento de los vientos Alisios y probablemente explica la voracidad de los incendios anuales en la vertiente sur y, simultáneamente, la ausencia de incendios en la vertiente norte. Claro está, unido a lo anterior, la vertiente sur está más expuesta al vapor caliente que emite la ciudad de Maracay (antigua Ciudad Jardín de Venezuela) y hoy en día con escasas áreas verdes por un cambio de uso del suelo exacerbado que genera más metros cuadrados de construcción, destrucción de sus árboles y áreas verdes en combinación con el incremento de la temperatura bajo los efectos del cambio climático.

Aunque Brown y Kappelle (2001) afirman la baja probabilidad de incendios en ecosistemas de $\mathrm{Bn}$, a su vez reconocen que las quemas pueden darse bajo condiciones atmosféricas especiales y poco frecuentes que favorezca su ocurrencia, incluso en proporciones importantes. Éstos pueden ser lo que identificó Córdova (2011a \& 2011b) en el Parque Nacional Waraira Repano (PNWR) (Guaraira Repano anteriormente Parque Nacional El Ávila). Córdova (2011a), analizó información térmica y ambiental mediante la utilización de técnicas de teledetección e identificó sectores urbanos y periurbanos, susceptibles a un mayor riesgo de incendios en caso de ocurrencia de anomalías climáticas para la ciudad de Caracas-Venezuela circunvecina del PNWR. Así mismo, Córdova (2011b) investigó las variaciones en los patrones de la temperatura superficial urbana, lo relacionó con el aumento de las temperaturas en la ciudad y con la incidencia de incendios forestales del PNWR y concluyó que el aumento de la temperatura de la ciudad de Caracas podría tener efectos colaterales sobre las coberturas vegetales del PNWR, aunado tanto por los cambios de uso del suelo como por el aumento de la temperatura ocasionado por anomalías climáticas que vienen ocurriendo en el mar Caribe e identificadas desde 2003. Así mismo, esto puede estar contribuyendo a los incendios en la vertiente sur del PNHP, acompañados de una importante acumulación de material muerto y hojarasca en los Bn, lo cual genera condiciones adecuadas para la combustión, como lo reconoció Zinck (1986), unido a los usos del suelo de las áreas circunvecinas del PNHP (Abarca \& Quiroz, 2005; Muñoz et al., 2006; Rebolledo, 2014).

Se cree que la situación identificada por Córdova (2011a \& 2011b) para el binomio CaracasPNWR podría igualmente estar ocurriendo en el binomio Maracay-PNHP porque este parque tiene 


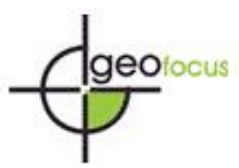

Rebolledo López, D. C., y Lores Ochoa, D. C. (2021). Evaluación espaciotemporal de la cobertura vegetal del parque nacional Henri Pittier, Venezuela. GeoFocus, Revista Internacional de Ciencia y Tecnología de la Información Geográfica (Artículos), 28, 25-58. http://dx.doi.org/10.21138/GF.742

la misma orientación y linda con una ciudad. En la ciudad de Maracay, aunque alberga menos población que Caracas, también se perciben los cambios de uso dentro del área urbana (cambios de residencias unifamiliares por multifamiliares con la eliminación de las áreas verdes de las residencias). Además, se cree que el PNHP podría aun ser más vulnerable a los incendios que el PNWR. Esto se sustenta en las condiciones climáticas, la cobertura vegetal y usos del suelo de las áreas circunvecinas de la vertiente sur de este parque (Abarca \& Quiroz, 2005).

Lo anterior se sostiene dado que los usos actuales del suelo en la vertiente sur del PNHP son más impactantes que los del PNWR. En el PNHP se dan uso tales como minero y militar con utilización de explosivos, agricultura con manejos agrícolas que implican la quema de los cultivos como es la caña de azúcar o urbano con quemas de desechos urbanos en los meses de menos precipitación, usos que tienen actividades que han originado sendos incendios (Muñoz et al., 2006) en los linderos del PNHP y que se extienden al parque mismo, cacería furtiva que de igual manera utilizan el fuego para acorralar y atrapar a sus presas; así como montañistas descuidados que hacen fogatas y al apagar las llamas lo hacen de manera superficial e inadecuada; así mismo como la presencia de pirómanos que queman la vegetación solo por el placer de ver la vegetación arder. En algunos casos estos incendios se apagan superficialmente y, sin embargo, por lo inadecuado de su combate se siguen propagando de manera silente por debajo de las hojarascas y unido a que están en áreas impenetrables para su combate, siguen propagándose (Abarca \& Quiroz, 2005; Muñoz et al., 2006; Rebolledo, 2014).

De la misma manera, Abarca y Quiroz (2005) reconocen como factores de riesgo de ignición los H siendo ésta la cobertura vegetal predominante en la vertiente sur, junto a la accesibilidad (vías asfaltadas y senderos en terracería) y los pisos altitudinales. Además del riesgo a la propagación, que está en función de factores físico-ambientales como vegetación, pendiente, altitud y dirección del viento; los cuales inciden en el comportamiento del fuego ya iniciado. Reflexionando y comparando los resultados de las investigaciones de Abarca y Quiroz (2005); Muñoz et al. (2006) y Zinck (1986) con la cuantificación del avance de cambios de cobertura vegetal obtenido en este estudio se evidencia que los usos del suelo y la cobertura de $\mathrm{H}$ son detonantes de los incendios en la vertiente sur, aunado a las características físicas, químicas y sobre todo las características orgánicas de los suelos y sus condicionantes climáticos identificadas por Zinck (1986).

De los párrafos anteriores se puede inferir que los incendios recurrentes e incontrolados anualmente son los responsables de los cambios de unidades de bosques a $\mathrm{H}$, destruyendo su cobertura vegetal y el sustento de sus suelos y con éstos la mayoría de los servicios ecosistémicos de los bosques. Éstos al ser destruidos por el fuego generan una serie de transformaciones en los suelos arrasados por la quema y en las áreas vecinas a esos incendios que crean simultáneamente condiciones ideales para que esas áreas ya no puedan convertirse de nuevo en $\mathrm{Bn}$. En cuanto a las áreas boscosas vecinas a las áreas quemadas, éstas se transforman y se convierten en entornos vulnerables para que el año próximo el fuego las afecte más, al punto de destruirlas. Así los incendios, año con año, siguen penetrando a las áreas boscosas, convirtiéndolas en $\mathrm{H}$, ya que la cobertura de bosque al estar más expuesta al contacto con los $\mathrm{H}$ cambian su microclima y así las condiciones de humedad disminuyen, haciéndolos más vulnerables para la quema. Esto ha sido identificado en los bosques lluviosos del Amazonas (Cochrane, 2001; 2003; Cochrane \& Laurance, 2002; 2003) y en los de Nueva Caledonia (Ibañez et al., 2013). Probablemente esto esté sucediendo 


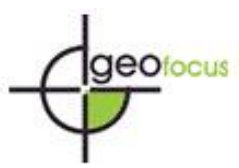

Rebolledo López, D. C., y Lores Ochoa, D. C. (2021). Evaluación espaciotemporal de la cobertura vegetal del parque nacional Henri Pittier, Venezuela. GeoFocus, Revista Internacional de Ciencia y Tecnología de la Información Geográfica (Artículos), 28, 25-58. http://dx.doi.org/10.21138/GF.742

en el PNHP donde se observan pérdidas de Bns, Bnb y $\mathrm{Br}$ unidades de vegetación que en condiciones normales son bosques muy húmedos; y en menor magnitud la explicación de las pérdidas de los Bsd y Bd.

Zinck (1986) encontró que los suelos orgánicos también contribuyen a la magnitud de la vulnerabilidad de los Bn ante la quema en comparación a los cambios de usos a agrícola vegetal o ganadería. En el PNHP los suelos del horizonte entre 10 a $20 \mathrm{~cm}$ de profundidad están compuesto por hojas muertas, secas, sueltas, enteras sin descomponer, con algunas hojas recién caídas y frecuentemente fragmentos de ramas, luego una capa compacta de hojas y micelios blancos de hongos conectadas con las raíces y con rara presencia de un horizonte completamente humificado. Al mismo tiempo, halló muy pocas raíces que penetren a más de 25 o $30 \mathrm{~cm}$ de profundidad. Así que en el primer horizonte los nutrientes son aprovechados por las florestas directamente de las hojas muertas en vías de descomposición mediante micorrizas y en el segundo horizonte, las raíces exploran la parte superior del suelo mineral. Ahora bien, al entrar los incendios a estos escenarios esta materia orgánica sirve de combustible altamente inflamable y así al ser quemados, estos suelos quedan expuestos a la pérdida de todas sus cualidades y su recuperación se vuelve improbable porque pierden la disposición de nutrientes requeridas para el desarrollo de los bosques.

Lo anterior se explica entendiendo que el ecosistema $\mathrm{Bn}$ es un mecanismo cerrado de aprovechamiento de nutrientes que se cree que está en estado de equilibrio. La vegetación natural recicla los nutrientes de tal manera que hay pocas salidas fuera del ecosistema. No obstante, si la vegetación es removida por incendios, entonces los nutrientes son liberados drásticamente de su ciclo cerrado y crean las condiciones ideales para que sean arrastrados por las lluvias (Zinck, 1986). Lo anterior también liberará a la atmósfera más $\mathrm{CO}_{2}$ que contribuirá con el efecto invernadero y, por ende, con el calentamiento climático.

Además, de la pérdida de las condiciones ideales para el sustento de los Bn ante incendios recurrentes e incontrolados; se presentan alteraciones en las condiciones de equilibrio de los bosques del PNHP que podrían estar activando procesos de erosión lineal y ésta desencadenaría movimientos en masa, con lupias de solifluxión, colada de barro, deslizamiento en plancha y despegues de suelo. Inclusive, se reconoce que las áreas boscosas ubicadas entre 1500 hasta 1800 msnm (Bnb) son las más vulnerables. Porque en estos bosques se evidencian mayores precipitaciones, saturación de los suelos y así llegan rápidamente a sus límites de consistencia, situaciones poco probables en las áreas donde la precipitación sea menor (Zinck, 1986).

\section{Acciones a llevar a cabo en el PNHP}

Los bosques deben preservarse, conservarse y protegerse y en especial los Bn por todos los servicios ecosistémicos que le brinda a los diferentes niveles regionales. En caso de pérdidas de esta cobertura sustento de la flora y de la propia flora, a la par, se perderá ante el fuego la protección del suelo que aportaban el follaje, la concentración de ramas y de troncos y la hojarasca. Así mismo se incinerará la densa red de raíces, por lo cual ya no atraparan materiales alterados in situ ni el agua de lluvia que se filtraba. Éstas serán arrastradas aguas abajo porque se habrán destruido los horizontes orgánicos que retardaban el escurrimiento superficial y favorecían la penetración o infiltración del agua al suelo ni habrá cationes que se movilicen en sus horizontes. Por lo cual, se 


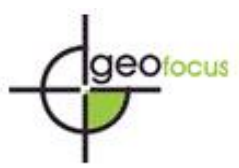

Rebolledo López, D. C., y Lores Ochoa, D. C. (2021). Evaluación espaciotemporal de la cobertura vegetal del parque nacional Henri Pittier, Venezuela. GeoFocus, Revista Internacional de Ciencia y Tecnología de la Información Geográfica (Artículos), 28, 25-58. http://dx.doi.org/10.21138/GF.742

perderá la humedad del suelo aportada por las precipitaciones y retenidas por los horizontes orgánicos que aseguraban una constante meteorización de las rocas y agua al ecosistema. Los suelos que contribuían a esa cobertura vegetal exuberante ya no dispondrán del material que sustentaba tal vegetación. Eso sí, los suelos plásticos serán más susceptibles a ser desplazados por movimientos de masa de tipo fluido (Zinck, 1986).

Aunque Madi et al. (2011) identificaron, de acuerdo a un indicador denominado Grado de Intervención (GDI), que el PNHP presentó $71.11 \%$ del área sin perturbación (28.89 \% perturbado), valor que les permitió afirmar que el PNHP se encuentra con un buen estado de conservación, una vez analizados los resultados de esta investigación, reportes de otras investigaciones que muestran las consecuencias que trae los cambios de cobertura de los bosques por incendios y en especial los Bn en cuanto a la merma de los servicios ecosistémicos, se cree que no es adecuada la afirmación de que el PNHP "presenta un buen estado de conservación". Argumentándose está inconformidad en que los parques nacionales son las áreas protegidas con mayor nivel de protección, de acuerdo a la legislación venezolana (Naveda, 2015) y que, bajo esta premisa, el porcentaje de pérdida de esta cobertura vegetal debería estar más cercana a cero y no con valores alrededor de $30 \%$.

De lo anterior se deduce que en la gestión del PNHP puede estar ocurriendo lo que identificó (Naveda, 2015) para las áreas protegidas de Venezuela. Es decir, en este parque están presentes: una planificación centralizada con un elevado peso normativo y sin coordinación administrativa (institucionalizado por la Gaceta Oficial en la Ley Orgánica para la Ordenación del Territorio), ausencia de capacidad de manejo directo con objetivos disimiles por el ente responsable de su gestión, presencia de conflictos de ocupación y uso del suelo, con ignorancia del poder de los gobiernos locales. Esto lo convierte en un parque inmanejable.

En concordancia con lo anterior, se le sugiere a los institutos rectores de este parque darle prioridad a las acciones de control que sean urgentes y que tengan mayor probabilidad de éxito, teniendo en cuenta las limitaciones de recursos, e integrarlas en el plan de ordenamiento, como lo identificaron Howort y Coronello (2004) para el monumento Natural Agustín Codazzi (Venezuela).

En el mismo orden de ideas, como señalan Aldrich y Hostettler (2000) para detener la pérdida futura de los Bn se requiere de: conciencia de los grupos de interés (stakeholder) acerca de los valores y servicios únicos de los $\mathrm{Bn}$, y de las opciones para conservarlos al tiempo que sostienen el desarrollo, compromiso para conservar y restaurar los valores de los Bn, capacidad para tratar las causas de la pérdida de Bn y lograr el apoyo de la sociedad para su conservación.

Por otra parte, adviértase que, a pesar de todo, y aunque es un tema que no se abarcó en este estudio y según el análisis espacial realizado por Los et al. (2021) sobre los Bn del mundo, este ecosistema puede estar presentando otra vulnerabilidad: ésta es ante el cambio climático, puesto que se evidenció que un aumento hipotético de la base de las nubes en $100 \mathrm{~m}$ en los trópicos reduciría la extensión espacial de las Bn en las Américas y en particular en África, pero la aumentaría en Asia. La alta sensibilidad de los Bn africanos al cambio climático está respaldada por evidencia a más largo plazo reportada en estudios paleoecológicos. Lo anterior se une a lo que expresaron a Biringer y Hansen (2005) para algunos bosques, cuando afirman la protección por sí sola no aumentará la resiliencia al cambio climático, en especial de los ecosistemas Bn. Una evidencia fue la encontrada 


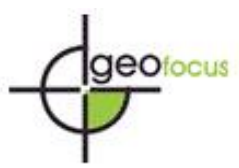

Rebolledo López, D. C., y Lores Ochoa, D. C. (2021). Evaluación espaciotemporal de la cobertura vegetal del parque nacional Henri Pittier, Venezuela. GeoFocus, Revista Internacional de Ciencia y Tecnología de la Información Geográfica (Artículos), 28, 25-58. http://dx.doi.org/10.21138/GF.742

en el Área del Patrimonio Mundial de los Bn y afirman que Australia experimentará una reducción de $50 \%$ en el hábitat con un calentamiento de un grado Celsius. Porque se estarían creando condiciones desfavorables para los anfibios y otras especies frías sin opciones de migración hacia las tierras altas a medida que las condiciones se vuelven más cálidas y secas.

\section{Conclusiones}

El análisis temporal de las imágenes del satélite Landsat 8 contribuyó a la identificación de las diferentes coberturas de vegetación del PNHP en los períodos estudiados.

Los valores de exactitud total obtenidos de los mapas de cobertura de los años 2014 y 2018 fueron de $90 \%$ y $87 \%$, respectivamente, junto al valor de K que resultó ser mayor a $85 \%$, para ambos casos. Esta exactitud permitió el análisis de la dinámica espaciotemporal de las coberturas vegetales del PNHP lo cual se evidencia a través de los resultados de las Matrices de Confusión.

La evaluación de los cambios de cobertura realizada a través del análisis de la Matriz de Detección de Cambio, para cada período, permitió la identificación de los cambios ocurridos. Estos cambios están marcados por el retroceso o disminución de las coberturas boscosas y el aumento de los H. Ésta dinámica de cambios está modificando la cubierta vegetal del PNHP. En este sentido, es esencial proteger y mantener los $\mathrm{Bn}$ en sus condiciones naturales ya que entre sus procesos y funciones ecológicas están la regulación del régimen de los ríos y el control de las inundaciones de las tierras bajas. La preservación de los Bn como reservas hidrológicas es una necesidad vital y corresponder a una estrategia prioritaria de la ordenación del territorio.

Los resultados obtenidos permiten inferir que la superficie perdida por las coberturas boscosas es ganada por los $\mathrm{H}$. Ésta es una información de mucho valor para los tomadores de decisión o responsables de resguardar las coberturas vegetales del PNHP porque las unidades de bosques son garantes de la mayor cantidad de servicios ambientales para los diferentes niveles territoriales (local, regional, nacional e internacional o global).

En especial en lo local los servicios ambientales utilizados por las comunidades a nivel local tanto las que habitan dentro del parque como las que residen en áreas circunvecinas, al norte y al sur del PNHP porque son las únicas fuentes del recurso agua para sus diversos usos. Estas comunidades se sirven de manera directa de los servicios ambientales y en especial del vital líquido, el agua. El PNHP es la única fuente de agua dulce para las poblaciones ubicadas en la vertiente norte y es complementaria para las comunidades de la vertiente sur, norte de la ciudad de Maracay, lo cual pone en riesgo la vida sustentable para estas comunidades. En lo regional, nacional e internacional o global, los servicios ambientales más reconocidos e importantes son la diversidad de ecosistema, especies y genes; y el secuestro o almacenaje de $\mathrm{CO}_{2}$ ya sea en los árboles como en la hojarasca. 


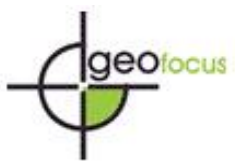

Rebolledo López, D. C., y Lores Ochoa, D. C. (2021). Evaluación espaciotemporal de la cobertura vegetal del parque nacional Henri Pittier, Venezuela. GeoFocus, Revista Internacional de Ciencia y Tecnología de la Información Geográfica (Artículos), 28, 25-58. http://dx.doi.org/10.21138/GF.742

\section{Referencias bibliográficas}

Abarca, O. I. y Quiroz G, J. G. (2005). Modelado cartográfico de riesgo de incendios en el Parque Nacional Henri Pittier. Estudio de caso: Vertiente sur, área colindante con la ciudad de Maracay". Agronomía Tropical 55(1):35-62. ISSN 0002-192X.

Abarca, O. y Rodríguez, S. (2005). Caracterización ambiental e hidráulico-estructural de la red de acueductos de la población de El Limón, estado Aragua. Agronomía Tropical. 55(2):1-21.

Aldrich, M. y Hostettler, S. (2000). Bosques Nublados Tropicales Montanos tiempo para la acción. Boletín arborvitae, Comité Holandés de la UICN, la Campaña de Aguas Vivientes del WWF y el Proyecto de Innovaciones Forestales de WWF/UIC. https://portals.iucn.org/library/sites/library/files/documents/2000-072.pdf Consultado 31-03-2021).

Andrade, E.M.; Palácio, H.A.Q.; Santos, J.C.N.; Brasil, J.B. y Navarro, J. (2019). Procesos ecohidrológicos y servicios ecosistémicos en regiones secas. Cuad. Soc. Esp. Cienc. For. 45(1): 241-250.

Armenteras, D., González, T. M., Vargas Ríos, O., Meza Elizalde, M. C. y Oliveras, I. (2020). Incendios en ecosistemas del norte de Suramérica: avances en la ecología del fuego tropical en Colombia, Ecuador y Perú. Caldasia. 42(1):1-16. https://www.jstor.org/stable/26872745?seq=1 (Consultado 31-03-2021).

Ataroff, M. (2001). Venezuela. En Kappelle, Maarten y Brown, Alejandro Diego. Bosques Nublados del Neotrópico. Instituto Nacional de Biodiversidad (InBio). Santo Domingo de HerediaCosta Rica, pp. 397-442.

Ataroff, M. y Rada, F. (2000). Deforestation impact on water dinamics in a Venezuelan Andean cloud forest. Ambio 29(7):440-444.

Audemar, F. A. y Singer, A. (2002). El alud torrencial del 6 de septiembre de 1987 en la cuenca del río El Limón, al norte de Maracay, Venezuela septentrional. En Desastres naturales en América Latina. México: Fondo de Cultura Económica, 385-408. https://www.researchgate.net/profile/Franck-

Audemard/publication/236147607 Movimientos en masa en el Macizo del Avila en diciembre _de_1999_Venezuela_septentrional/links/004635165f90a47d7c000000/Movimientos-en-masa-enel-Macizo-del-Avila-en-diciembre-de-1999-Venezuela-septentrional.pdf (Consultado 14/07/2021).

Beebe, W. y Crane, J. (1948). Ecología de Rancho Grande, una selva nublada subtropical en el norte de Venezuela. Boletín de la Sociedad de Venezolana de Ciencias Naturales. 11(73):271-258.

Berlanga Robles, C. A., García-Campos, R. R., López-Blanco, J., y Ruiz Luna, A. (2009). Patrones de cambio de coberturas y usos del suelo en la región costa norte de Nayarit (1973-2000). Investigaciones Geográficas, (72), 7-22.

Biringer, J. y Hansen, L. J. (2005). Restoring forest landscapes in the face of climate change. En Forest Restoration in Landscapes (pp. 31-37). Springer, New York, NY. https://www.thevespiary.org/library/Files_Uploaded_by_Users/llamabox/Botany/Forest\%20Restora 
Rebolledo López, D. C., y Lores Ochoa, D. C. (2021). Evaluación espaciotemporal de la cobertura vegetal del parque nacional Henri Pittier, Venezuela. GeoFocus, Revista Internacional de Ciencia y Tecnología de la Información Geográfica (Artículos), 28, 25-58. http://dx.doi.org/10.21138/GF.742

tion\%20in\%20Landscapes\%20-

\%20S.Mansourian,\%20et\%20al.,\%20(Springer,\%201986)\%20WW.pdf\#page=53

(Consultado 14/07/2021).

Brown, A. D. y Kappelle, M. (2001). Introducción a los bosques nublados del neotrópico: una síntesis regional. En Kappelle, M. y Brown, A. D. Bosques nublados del neotrópico (25-40). Instituto Nacional de Biodiversidad (INBio), Santo Domingo de Heredia-Costa Rica. https://www.researchgate.net/profile/Maarten-

Kappelle/publication/254778948 Introduccion a los Bosques Nublados/links/55aca26c08ae815a 042b19f1/Introduccion-a-los-Bosques-Nublados.pdf (Consultado 11-07-2021).

Bruijnzeel, S. (L. A.) y Lawrence S. H. (2001). Tiempo decisivo para las selvas de neblina. Asuntos y problemas relacionados con el agua en los trópicos húmedos y otras regiones cálido-húmedas. IHP Programa Trópicos Húmedos Serie No. 13. UNESCO. https://www.hydrology.nl/images/docs/ihp/2000_Tiempo_decisivo_para_las_selvas_de_neblina.pdf (Consultado 14-07-2021).

Cardozo López, A. (1999). Comparación florística y estructural entre la selva nublada baja y la selva nublada superior, Parque Nacional Henri Pittier, estados Aragua y Carabobo. Venezuela. Tesis Doctoral en Ciencias. Facultad de Ciencias. Universidad Central de Venezuela. CaracasVenezuela. 366 pp.

Cochrane, M. A. (2001). Synergistic interaction between habitat fragmentation and fire in evergreen tropical forests. Conservation Biology. 15(6):1515-1521.

Cochrane, M. A. (2003). Fire science for rainforests. Nature. 421:913-919.

Cochrane, M. A. y Laurance, W.F. (2002). Fire as a large-scale edge effect in Amazonian forests. Journal of Tropical Ecology. 18(03):311-325.

Cochrane, M. A. y Laurance, W. F. (2008). Synergisms among fire, land use, and climate change in the Amazon. AMBIO: A Journal of the Human Environment. 37(7):522-527.

Córdova, K. (2011a). Geotecnología espacial aplicada al estudio del clima urbano: Análisis térmico superficial en la ciudad de Caracas-Venezuela. En Revista Geográfica Venezolana, 52(2):31-46. http://www.saber.ula.ve/bitstream/handle/123456789/34395/articulo2.pdf?sequence=1\&isAllowed $=$ y (Consultado 14-07-2021).

Córdova Sáez, K. (2011b). Impactos de las islas térmicas o islas de calor urbano, en el ambiente y la salud humana. Análisis estacional comparativo: Caracas, octubre-2009, marzo-2010. Terra Nueva Etapa, 26(42):95-122. https://www.redalyc.org/pdf/721/72121706005.pdf (Consultado 14-07-2021.

Costanza, R., d'Arge, R., de Groot, R., Farberk, S., Grasso, M., Hannon, B., Limburg, K., Naeem, S., O’Neill, R. V., Paruelo, J., Raskin, R. G., Suttonkk, P. y Van den Belt, M. (1997): "The value of the world's ecosystem services and natural capital". Nature, 387(15):253-260.

Dudley, N. y Stolton, S. (2003). Running Pure: The importance of forest protected areas to drinking wáter. World Bank / WWF Alliance for Forest Conservation and Sustainable Use. https://openknowledge.worldbank.org/bitstream/handle/10986/15006/292830Running0pure.pdf (Consultado 18-07-2021). 


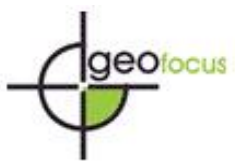

Rebolledo López, D. C., y Lores Ochoa, D. C. (2021). Evaluación espaciotemporal de la cobertura vegetal del parque nacional Henri Pittier, Venezuela. GeoFocus, Revista Internacional de Ciencia y Tecnología de la Información Geográfica (Artículos), 28, 25-58. http://dx.doi.org/10.21138/GF.742

Eastman, J. R., McKendry, Jean, Fulk Michele A. (1995). Explorations in geographic information systems technology. En Vol. 1 Change and time series analysis. United Nations Institute for Training and Research, Geneva. 119 pp.

Fernández Badillo, A. (1997). El Parque Nacional Henri Pittier. Tomo I: Caracterización físicoambiental. Trabajo de Ascenso, categoría Titular. Facultad de Agronomía. Universidad Central de Venezuela. Maracay-Venezuela. 270 pp.

García Peña, R. E. y Silva Viera, M. I. (2013). Las ABRAE versus las áreas protegidas en Venezuela. $\quad$ En Copérnico $\quad X \quad$ (19):27-39. http://www.revencyt.ula.ve/storage/repo/ArchivoDocumento/copernico/n19/art04.pdf (Consultado 30-03-2021).

Howorth, R. y Colonnello, G. (2004). Sucesión secundaria como consecuencia de diferentes tipos de usos de la tierra en bosques pluviales montanos en la cordillera de La Costa Central (Venezuela). Memoria de la Fundación La Salle de Ciencias Naturales, 161(162):137-165.

Huber, O. (1986). La Selva Nublada de Rancho Grande Parque Nacional "Henri Pittier" El Ambiente Físico, Ecología Vegetal y Anatomía Vegetal. En Huber, O. La selva nublada de Rancho Grande Parque Nacional Henri Pittier. Fondo Editorial Acta Científica Venezolana, Caracas. pp. 3166.

Ibañez, T., Hély, C. y Gaucherel, C. (2013). Sharp transitions in microclimatic conditions between savanna and forest in New Caledonia: Insights into the vulnerability of forest edges to fire. Austral Ecology. 38(6):680-687.

Institut Cartogràfic de Catalunya. (1999a). Ortofotomapas ráster ortofotomapas Ocumare. Misión 0202155 del 27 y 28 de febrero de 1998 España, disponible en el IGVSB.

Institut Cartogràfic de Catalunya. (1999b). Ortofotomapas ráster ortofotomapas Colonia Tovar. Misión 0202155 del 27 y 28 de febrero de 1998, España, disponible en el IGVSB.

Institut Cartogràfic de Catalunya. (1999c). Ortofotomapas ráster ortofotomapas Girardot. Misión 0202155 del 27 y 28 de febrero de 1998 España, disponible en el IGVSB.

Lentino, M. (1990). Informe de las actividades realizadas en el Parque Nacional Henri Pittier, estado Aragua, durante el periodo septiembre de 1989 hasta abril 1990. https://www.researchgate.net/profile/Miguel-

Lentino/publication/238768794_INFORME_DE_LAS_ACTIVIDADES_REALIZADAS_EN_EL_ PARQUE NACIONAL HENRI PITTIER ESTADO ARAGUA DURANTE EL PERIODO S EPTIEMBRE DE 1989 HASTA ABRIL 1990/links/59c5127a458515548f28b013/INFORMEDE-LAS-ACTIVIDADES-REALIZADAS-EN-EL-PARQUE-NACIONAL-HENRI-PITTIERESTADO-ARAGUA-DURANTE-EL-PERIODO-SEPTIEMBRE-DE-1989-HASTA-ABRIL1990.pdf (Consultado 09-07-2021).

Los, Sietse O., Street-Perrott, F. A., Loader, N. J. y Froyd, C. A. (2021). Detection of signals linked to climate change, land-cover change and climate oscillators. Remote Sensing of Environment. 260(112431):1-20.

https://www.sciencedirect.com/science/article/pii/S0034425721001498

(Consultado 15-07-2021). 
Rebolledo López, D. C., y Lores Ochoa, D. C. (2021). Evaluación espaciotemporal de la cobertura vegetal del parque nacional Henri Pittier, Venezuela. GeoFocus, Revista Internacional de Ciencia y Tecnología de la Información Geográfica (Artículos), 28, 25-58. http://dx.doi.org/10.21138/GF.742

Madi, Y., Vázquez, J., León, A., y Rodrígues, J. (2011). Estado de conservación de los bosques y otras formaciones vegetales en Venezuela. https://www.researchgate.net/profile/Jose-VazquezRodriguez/publication/308174681_ESTADO_DE_CONSERVACION_DE_LOS_BOSQUES_Y_O TRAS_FORMACIONES_VEGETALES_EN_VENEZUELA/links/57dc785f08ae72d72ea69533/E STADO-DE-CONSERVACION-DE-LOS-BOSQUES-Y-OTRAS-FORMACIONESVEGETALES-EN-VENEZUELA.pdf (Consultado 20-07-2021).

Maillard, O., Aguilera, V. y Uyuni, G. (2019). Evaluación de la detección de la deforestación y degradación usando ClaSlite: estudio de caso en un área montañosa de transición en Bolivia". Kempffiana15 (1):1-16, ISSN: 1991-4652.

Martin, R. M. (2005). Deforestación, cambio de uso de la tierra y REDD. Revista internacional de silvicultura e industrias forestales, 59(1):3-11. http://www.fao.org/3/i0440s/i0440s02.htm (Consultado 11-02-2008).

Ministerio de la Secretaría de la Presidencia (MSP). (1995). Plan de Ordenamiento y Reglamento de Uso Parque Nacional "Henri Pittier". República de Venezuela. Resolución 350 de 24 de noviembre de 1995Compendio Legal Sobre Áreas Protegidas Estrictas de Venezuela. Caracas Centro Internacional de Ecología $\quad$ Tropical (CIET). https://musguito.net.ve/anapro/ecosig.org.ve/pdf/V_PN_Medanos_de_Coro_PORU.pdf (Consultado 11-02-2008).

Muñoz, D., Castillo, R., y Salas, V. (2006). Estado de Conservación del Parque Nacional Henri Pittier. Bioparques: Asociación Civil para la Conservación de los Parques Nacionales. 35 pp. https://es.slideshare.net/bioparques/perfil-pn-henripittier2005 (Consultado 27-03-2021).

Naveda, J. (2015). Cambio climático y áreas protegidas de Venezuela: Posibles efectos ambientales y su contribución y mitigación. Informe del Instituto Nacional de Parques. Dirección de Parques Nacionales. Caracas-Venezuela. Recuperado en https://www.academia.edu/41195406/Cambio clim\%C3\%A1tico_y \%C3\%A1reas protegidas de Venezuela posibles efectos ambientales y su contribuci\% $3 \% \mathrm{~B} 3 \mathrm{n}$ a la mitigaci\% $\mathrm{C} 3 \% \mathrm{~B} 3 \mathrm{n} \_\mathrm{y}$ adaptaci\%C3\%B3n (Consultado 15-07-2021).

Organización de las Naciones Unidas para la Agricultura y la Alimentación (FAO). 2000. FRA2000 Bibliografía comentada. Cambios en la cobertura forestal. Venezuela. Departamento de Montes. Programa de evaluación de los recursos forestales. Documento de trabajo 39. Roma-Italia. 31 pp.

Osuna Osuna, A. K., Díaz Torres, J. De J., De Anda-Sánchez, J., Villegas García, E., Gallardo Valdez, J. y Davila Vázquez, G. (2015). Evaluación de cambio de cobertura vegetal y uso de suelo en la cuenca del río Tecolutla, Veracruz, México; período 1994-2010. Ambiente \& Água-An Interdisciplinary Journal of Applied Science, 10(2): 350-362.

Ramsey III, E. W., Gene A. N. y Sapkota, S. K. (2001). Coastal change analysis program implemented in Louisiana. Journal of Coastal Research, No. 17, pp. 53-71. ISSN 0749-0208.

Rebolledo López, D. C. (2014). Beneficios Económicos de los Bosques Nublados del Parque Nacional Henri Pittier. Tesis de Doctorado en Ciencias Mención Ecología. Instituto de Zoología y Ecología Tropical. Facultad de Ciencias. Universidad Central de Venezuela. Caracas-Venezuela, 12, 1-12, 2-2pp. 


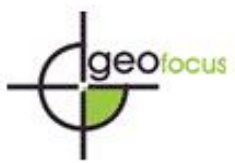

Rebolledo López, D. C., y Lores Ochoa, D. C. (2021). Evaluación espaciotemporal de la cobertura vegetal del parque nacional Henri Pittier, Venezuela. GeoFocus, Revista Internacional de Ciencia y Tecnología de la Información Geográfica (Artículos), 28, 25-58. http://dx.doi.org/10.21138/GF.742

República de Venezuela. (1937). Declaratoria del Parque Nacional Rancho Grande (Hoy día Parque Nacional Henri Pittier). Decreto No 102 de 13/02/1937. Gaceta Oficial No 19.188 del 13de febrero de 1937.

Ríos Cabrera, M. M., Ruiz Dáger, M., Maduro Rojas, R. y García, H. (2010). Estudio exploratorio de las propiedades físicas de suelos y su relación con los deslizamientos superficiales: Cuenca del río Maracay, estado Aragua-Venezuela. Revista geográfica venezolana, 51(2):225-247.

Rosas Rangel, D. M., Mendoza, M. E., Gómez Tagle, A. y Tobón Marín, C. (2019). Avances y desafíos en el conocimiento de los bosques mesófilos de montaña de México. Madera y bosques, 25(1):1-19.

Sánchez Ramos, Alexis Alejandro. (2009). Análisis Multitemporal de la Cobertura de la Tierra en la Cuenca del Valle de Jesús de Otro entre los años 2000-2006, aplicando técnicas de teledetección. Tesis de Maestría Universidad Nacional Autónoma de Honduras. 58, 106 pp.

Perra Ruiz, P., Moré, G. y Pons Fernández, X. (2008). “Consecuencias en la cartografía de cultivos mediterráneos de la combinación de datos ráster-vector: enriquecimiento de una base SIGPAC a través de teledetección". Espacio, Tiempo y Forma. Serie VI, Nueva época. Geografía, 1:59-69.

Silva, J. F. (2003). Sabanas. Aguilera, M.; A. Azócar y E. González J., Eds.), Biodiversidad en Venezuela. Tomo II. Cap. 42 (pp. 31-66). Fundación Polar y FONACIT. Caracas-Venezuela.

Stadtmüller, T. (1986). Cloud Forests in the Humid Tropic. Bibliographic Review. The United Nations University, Centro Agronómico Tropical de Investigación y Enseñanza. Turrialba-Costa Rica.

Umaña Gomeza, G., Romero P. R., y Rodriguez S. M. (2015). Aproximación a un balance hídrico del Bosque de Niebla. Construcción e implementación de un CASCC_2 para recolección y cuantificación de la precipitación horizontal en Guasca, Colombia. Universidad de Los Andes Colombia, Facultad de Ingeniería.

https://repositorio.uniandes.edu.co/bitstream/handle/1992/17643/u713972.pdf?sequence=1(Consult ado 10-07-2021).

Unión Mundial para la Naturaleza (IUCN). (2001). Protected Areas Programme. Cities and Protected Areas. Parks. 11(3):1-52.

https://www.iucn.org/sites/dev/files/import/downloads/parks11_3.pdf (Consultado 10-07-2021).

Verea, C. y Solórzano, A. (2000). Avifauna asociada al soto bosque musgoso del Pico Guacamaya, Parque Nacional Henri Pittier, Venezuela". Interciencia, 36(5), 324-330.

Verea, C. y Díaz, M. (2005). Variaciones temporales en la composición de la comunidad de aves de un sotobosque deciduo del Parque Nacional Henri Pittier, norte de Venezuela. Memoria de la Fundación La Salle de Ciencias Naturales, 163: 19-36.

Verea, C., Fernández Badillo, A. y Solorzano, A. (2000). Variación en la composición de las comunidades de aves de sotobosque de dos bosques en el norte de Venezuela. Ornitol. Neotrop, 11, 65-79.

Vielma Mendoza, M. (2020). Focos de calor e incendios forestales y de vegetación en Venezuela durante la temporada de sequía entre 2019 y 2020. Observatorio de Ecología Política de Venezuela 


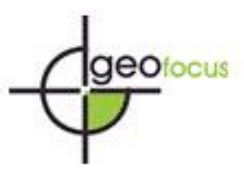

Rebolledo López, D. C., y Lores Ochoa, D. C. (2021). Evaluación espaciotemporal de la cobertura vegetal del parque nacional Henri Pittier, Venezuela. GeoFocus, Revista Internacional de Ciencia y Tecnología de la Información Geográfica (Artículos), 28, 25-58. http://dx.doi.org/10.21138/GF.742

(O.E.P). https://www.ecopoliticavenezuela.org/2020/07/06/focos-de-calor-e-incendios-forestales-yde-vegetacion-en-venezuela-durante-la-temporada-de-sequia-entre-2019-y-

2020/\#: :text=En\%201a\%20temporada\%20de\%20sequ\%C3\%ADa,la\%20biodiversidad\%20y\%20la s\%20cuencas (Consultado 01-03-2021).

Zinck, A. (1986a). Los suelos. Características y fragilidad de los suelos en ambiente de selva nublada: el ejemplo de Rancho Grande. Huber, O. La selva nublada de Rancho Grande Parque Nacional Henri Pittier. El ambiente físico, ecología vegetal y anatomía vegetal. (pp. 31-66). Fondo Editorial Acta Científica Venezolana, Caracas-Venezuela. 